\title{
INCORPORATING LAWYERS ON THE INTERPROFESSIONAL TEAM TO PROMOTE HEALTH AND HEALTH EQUITY
}

\author{
Charity Scott, J.D., MSCM*
}

TABLE OF CONTENTS

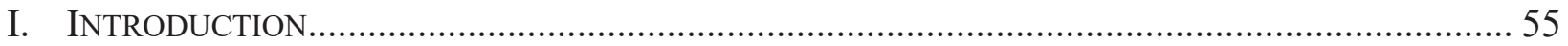

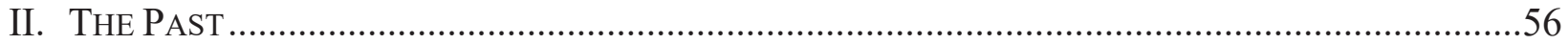

A. Health Care Disparities Begin to Get the Attention of the Federal Government

B. Lawyers Not Seen on the Health Team

III. THE PRESENT

A. Progress on the IOM's Recommendations to Address Health Disparities

B. Shift in Mindset: The Socioeconomic Determinants of Health.

C. Lack of Progress in Eliminating Health Disparities

D. Institutional and Structural Barriers to Reducing Health Disparities

E. Health (and Health Equity) in All Policies

IV. THE FUTURE.. .83

A. Promising Directions for Legal Interventions to Promote Health and Health Equity

B. Professional and Graduate Education for the Future

1. Progress within the Health Professions

2. Next Steps: Incorporating the Legal Profession

V. CONCLUSION.

* Catherine C. Henson Professor of Law at Georgia State University College of Law. I sincerely thank the INDIANA HEALTH LAW REVIEW and its gracious editors for the opportunity to kick-off their day-long symposium on October 16, 2015, with the keynote address on which this article is based. The symposium offered numerous, excellent perspectives on "Interprofessional Collaboration in Public Health Law and Policy: Moving the Needle on Social Determinants of Health." Disclosure: The Robert Wood Johnson Foundation awarded Georgia State College of Law and its Center for Law, Health \& Society, which I directed at the time, a grant to create and implement a 2014-2015 faculty fellowship program on The Future of Health Law Education, which is discussed in this article. I was the lead faculty and project director for this faculty fellowship program. 


\section{INTRODUCTION}

Legal, health care, and public health professionals should all be on the same educational and collaborative practice team to promote health and health equity. Such interprofessional collaboration historically may have raised questions or even suspicions in some circles. Too often, many in the legal and medical professions have viewed themselves as adversaries, not allies, ${ }^{1}$ and health care professionals and public health professionals have long carried out their respective work efforts in separate professional silos. ${ }^{2}$ These perspectives have been slowly changing in recent years-and it is a welcome, if too long overdue, shift in our understanding for how lawyers can work with health-related professionals, and the health-related professionals with each other, to address a range of health care and public health challenges in this country.

This article explores the past, present, and potential future role for lawyers in working with health-related professionals, policy-makers, and advocates to promote health and health equity in the United States. Part II begins by reviewing our past understandings about health disparities and until recently the relative absence of lawyers from the cohort of professionals who have been concerned with addressing them. Part III describes the current lack of progress in reducing health disparities despite considerable national attention to the problem over the last decade. It reviews our evolving understanding of how socioeconomic factors and entrenched race and class-based societal structures contribute to ill health and health disparities, and how collaborations among public and private stakeholders beyond the traditional health care and public health sectors are needed to achieve lasting health equity. Part IV examines promising new directions for how laws and lawyers can contribute to addressing health disparities. It also looks to the future of interprofessional collaboration by exploring the role of professional and graduate education in fostering opportunities to begin interprofessional teamwork to improve health and health equity while young professionals-to-be are in training.

${ }^{1}$ William M. Sage, The Lawyerization of Medicine, 26 J. HeAlth PoL., POL'Y \& L. 1179, 1181-83 (2001), http://muse.jhu.edu [https://perma.cc/SHL4-JADM] ("If not for medical malpractice litigation, organized medicine and the bar might have been allies ... Tort reform, of course, brought the medical profession into even greater conflict with lawyers").

2 Julio Frenk et al., Health Professionals for a New Century: Transforming Education to Strengthen Health Systems in an Interdependent World, 376 LANCET, 1923-27 (2010) (observing that "[1] audable efforts to address these deficiencies [in the education of health professionals] have mostly floundered, partly because of the so-called tribalism of the professions - i.e., the tendency of the various professions to act in isolation from or even in competition with each other ... The present division of labor between the various health professions is a social construction resulting from complex historical processes around scientific progress, technological development, economic relations, political interests, and cultural schemes of values and beliefs"); see also Committee on Integrating Primary Care and Public Health, Primary Care and Public Health: Exploring Integration to Improve Population Health, Inst. OF MED. 4, 45 ( 2012), http://www.nap.edu [https://perma.cc/2BZ2-4WMV] [hereinafter IOM Primary Care] (commenting that "[p]rimary care and public health presently operate largely independently ... there are no broadly accepted or implemented models of primary care and public health integration"). 


\section{The PAST}

\section{A. Health Care Disparities Begin to get the Attention of the Federal Government}

Researchers have known for decades that significant disparities exist in both the health outcomes of, and in the kinds and quality of health care provided to, minority and non-minority populations in our country. In 1984, within a year of her becoming Secretary of the U.S. Department of Health and Human Services ("HHS"), Margaret M. Heckler sent Congress an annual report card on the health status of Americans which showed that, while there had been overall health improvement among Americans, "there was a continuing disparity in the burden of death and illness experienced by Blacks and other minority Americans as compared with our nation's population as a whole." '3 She promptly established a Task Force on Black and Minority Health, which comprehensively investigated the health status of blacks and other minority Americans.

The Task Force issued its report in 1985, which became known as the "Heckler Report." The Report confirmed that, "[a]lthough tremendous strides have been made in improving the health and longevity of the American people, statistical trends show a persistent, distressing disparity in key health indicators among certain subgroups of the population." 5 The Report found that between 1979 and 1981, an average of about 139,000 blacks under the age of seventy died every year. ${ }^{6}$ To quantify the number of deaths that would not have occurred if minority mortality rates had equaled non-minority mortality rates, the Report utilized the statistical technique of measuring the number of "excess deaths." It found that about 59,000 of these annual deaths (or 42.3\%) were "excess deaths"-that is, they would not have occurred had blacks experienced the same mortality rates as whites. ${ }^{8}$ The Report also found a gap of 5.6 years between the life expectancy of whites $(75.2$ years) and blacks (69.6 years-the same life expectancy as whites had had thirty years earlier in 1950). ${ }^{9}$ It also noted that blacks had twice the rate of infant mortality as whites. ${ }^{10}$ Figure 1 graphically illustrates the persistent life-expectancy gap between blacks and whites as found by the Heckler Report for the thirty years prior to its issuance.

3 Margaret M. Heckler, Report of the Secretary's Task Force on Black and Minority Health, Secretary's Foreword and Charge to the Task Force, ix (1985), http://minorityhealth.hhs.gov [https://perma.cc/7R9T-BFHG] [hereinafter Heckler Report].

${ }^{4}$ Centers for Medicare and Medicaid Services, Thirty Years Later, the "Heckler Report" Continues to Influence Efforts to Improve Minority Health, CMS.GOv, https://www.cms.gov [https://perma.cc/B94Y-VTYL] (last updated Feb. 17, 2016, 12:11 PM).

${ }^{5}$ Heckler Report, supra note 3, at 2.

${ }^{6}$ Id. at 70.

${ }^{7}$ Id. at 3-4.

${ }^{8}$ Id. at 5,70 .

${ }^{9} \mathrm{Id}$. at 2 .

${ }^{10} \mathrm{Id}$. at 2, 70 . 


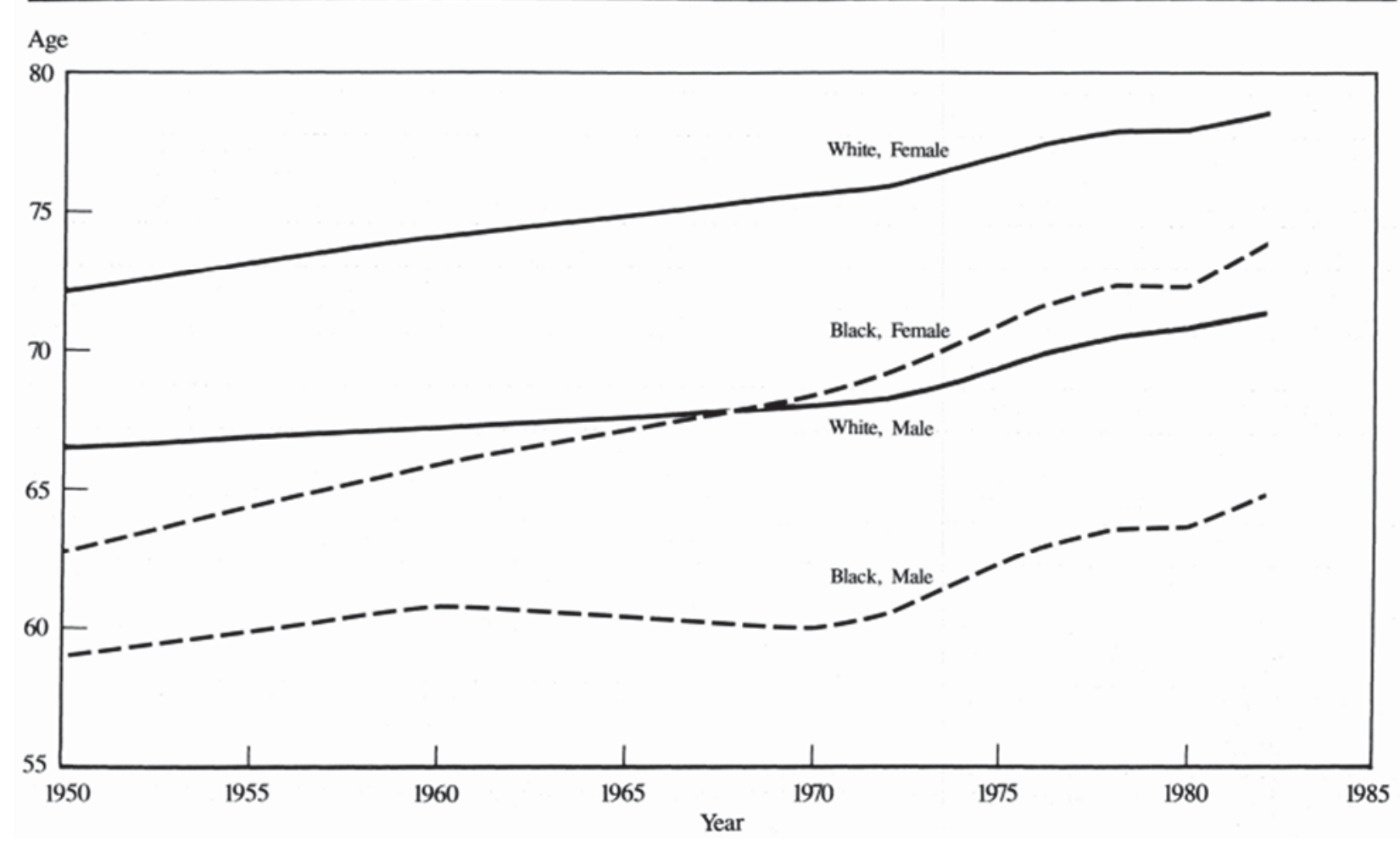

Figure 1. Life Expectancy at Birth, According to Race and Sex: United States, 1950 1983. ${ }^{11}$

The Task Force Chair acknowledged the Heckler Report represented the first time that HHS had consolidated minority health issues into one report and said it should serve "as the generating force for an accelerated national assault on the persistent health disparities which led [the Secretary] to establish the Task Force." "12 The Task Force recommended numerous ways to address the health disparities it found, including: a suggested public awareness campaign to disseminate health information and education materials specifically designed for minorities; ${ }^{13}$ increased patient education responsive to minority populations and sensitive to minority cultural and language needs ${ }^{14}$ improved delivery and financing of health services to facilitate minority access and to be more culturally acceptable; ${ }^{15}$ increased availability and accessibility of health professionals to minority communities; ${ }^{16}$ fostering of the federal government's coordination with and technical assistance to state and local communities to build capacity for meeting health needs of minority

\footnotetext{
${ }^{11} I d$. at 66.

${ }^{12} I d$. at vii.

${ }^{13}$ Id. at $9-13$.

${ }^{14} \mathrm{Id}$. at $13-14$.

${ }^{15}$ Id. at $15-20$.

${ }^{16} \mathrm{Id}$. at 21-24.
} 
populations; ${ }^{17}$ improved minority health data collection and use ${ }^{18}$ and development of a research agenda for minority health. ${ }^{19}$

These priorities for addressing health disparities-public awareness, patient education, culturally competent provision of health care services, recruitment of minority health professionals, better data collection, and more research on minority health-will be reiterated time and again in the ensuing three decades in national calls for public and private efforts to reduce health disparities. Unfortunately, the Heckler Report and subsequent national reports have had little impact on actually reducing health disparities. ${ }^{20}$ And while the subsequent reports have offered a limited role for enforcement of antidiscrimination laws to address health disparities, the Heckler Report's recommendations did not offer any role for law in addressing health disparities.

Despite the Heckler Report's careful chronicling of clear health disparities and its forceful recommendations for action to address them, it was not until the release in 2003 by the Institute of Medicine ("IOM") of its report, UNEQUAL TREATMENT: CONFRONTING RACIAL AND ETHNIC DISPARITIES IN HEALTH CARE, ${ }^{21}$ that the evidence of racial and ethnic disparities in health status and health care garnered significant national attention. Relying on an in-depth review of research literature going back to 1992, the IOM report made its first principal finding, which echoed the Heckler Report's findings almost twenty years earlier: "Racial and ethnic disparities in healthcare exist. These disparities are consistent and extensive across a range of medical conditions and healthcare services, are associated with worse health outcomes, and occur independently of insurance status, income, and education, among other factors that influence access to healthcare. These disparities are unacceptable." ${ }^{22}$ The IOM report made sweeping recommendations that were very similar to the Heckler Report before it. These recommendations included: increased awareness of racial and ethnic disparities in health care among the general public, key stakeholders, and health care providers, ${ }^{23}$ more cross-cultural education to improve health care professionals' ability to provide quality care to diverse patient populations, ${ }^{24}$ more data collection and monitoring of progress toward eliminating health disparities, ${ }^{25}$ and more research on the sources of health disparities, promising interventions, and barriers to eliminating disparities. ${ }^{26}$

The IOM report took a limited view of the role of law as an intervention to address racial and ethnic disparities, focusing predominantly on legal remedies under civil rights laws. This limited view may have been due at least in part for two reasons: the report focused on disparities in health

${ }^{17} \mathrm{Id}$. at $25-30$.

${ }^{18} \mathrm{Id}$. at 31-36.

${ }^{19} \mathrm{Id}$. at $38-45$.

${ }^{20}$ See infra notes 97-109 and accompanying text (discussing lack of progress nationally in eliminating health disparities).

${ }^{21}$ COMmitTeE ON Understanding AND Eliminating RaCial AND ETHNiC DisParities IN Health Care, institute of Medicine, Unequal Treatment: Confronting Racial and Ethnic Disparities in Health Care, Washington, D.C.: The National Academies Press (Brian D. Smedley et al. eds., 2003) [hereinafter UNEQUAL TREATMENT report].

${ }^{22}$ Id. at 79.

${ }^{23}$ Id. at 124.

${ }^{24}$ Id. at 214.

${ }^{25}$ Id. at $233-34$.

${ }^{26}$ Id. at $242-43$. 
care access and provision, and it framed the problem of health care disparities largely as one of historical discrimination and racial and ethnic bias among health care providers and within society. 27 The report found, "Racial and ethnic disparities in healthcare occur in the context of broader historic and contemporary social and economic inequality, and evidence of persistent racial and ethnic discrimination in many sectors of American life ...."28 Additionally, the report later stated, "The committee finds strong, but circumstantial evidence for the role of bias, stereotyping, prejudice, and clinical uncertainty from a range of sources, including studies of social cognition and 'implicit' stereotyping, but urges more research to identify how and when these processes occur. $^{29}$

In the IOM's reasoning, if bias and prejudice existed in health care, then unlawful discrimination was a possible contributor to health disparities. Thus it recommended enhanced enforcement of the civil rights laws, principally Title VI of the 1964 Civil Rights Act, prohibiting discrimination in health care, through increased funding of the HHS Office for Civil Rights. ${ }^{30}$ Because the focus of the IOM's report was on disparities in health care, and not yet on the broader contribution of social determinants on health, it understandably framed its principal recommended legal intervention narrowly on addressing potential discrimination in the provision of health care services.

The IOM's focus on discrimination in health care as a major, if not the major contributor to health disparities, was understandable for its time, as health in national discourse was then largely about health care. And it remains true that many routine practices among health care providers and insurers have contributed to disparate negative health impacts on minority patients. ${ }^{31}$ Yet, this narrow focus on health care's contribution to the problem of health disparities reinforced the siloed professional ways of thinking about minority health. Health care professionals historically focused their efforts to improve health on the provision of medical treatment to individual patients, leaving the social and environmental conditions that promote or worsen health to the attention of public health professionals. For their part, public health professionals were at pains to distinguish their role from the provision of medical care. These professional silos would begin to break down only very recently.

27 Id. at 13-15; 155-59 (The report identified a few other "legal, regulatory, and policy interventions to eliminate racial and ethnic disparities in health care," including measures to equalize the health products and services that publicly-funded health plans (such as Medicaid) offer to its enrollees with those offered by private plans; possible use of medical tort law and the Emergency Treatment and Active Labor Act, 42 U.S.C. $\$ 1395$ dd (1995), to address discriminatory health care practices; the report gave particular attention, however, to the "unfilled potential of Title VI").

${ }^{28}$ UNEQUAL TREATMENT report, supra note 19, at 123.

${ }^{29}$ Id. at 178 .

${ }^{30} \mathrm{Id}$. at $187-88$.

${ }^{31}$ Sidney D. Watson, Section 1557 of the Affordable Care Act: Civil Rights, Health Reform, Race, and Equity, 55 How. L.J. 855, 867-68 (2012) (discussing how "a whole array of business practices that have become standard operating procedures for providers and insurers have a disproportionate adverse impact on minority patients and tend to segregate treatment on the basis of race"). 


\section{B. Lawyers Not Seen on the Health Care or Public Health Teams}

Both health care and public health professionals historically did not see a role for lawyers on their respective teams to improve the health of their patients or the public. On the contrary, feelings of antagonism have often existed on the part of health care professionals toward lawyers and the law, viewing them through a narrow lens as offering only threats of spurious lawsuits for medical malpractice or burdensome governmental fishing expeditions for regulatory malfeasance by providers. ${ }^{32}$ It is thus not surprising that the primary recommendation involving a role for law and lawyers in the IOM's report was for increased enforcement of existing laws against providers. Such a limited role was the only role that most health care and public health professionals had ever seen for law and lawyers. It was not until the 21 st century that a major government agency or private public health organization paid significant attention to the role of law in promoting society's health. ${ }^{33}$

Health professionals' resistance to collaborating with lawyers to promote the health of patients and the community has been matched by lawyers' equally narrow vision of themselves. Lawyers have not typically viewed their role beyond working as legal counsel for, or as advocates against, health care providers (individuals or institutions) or public health agencies or organizations. Lawyers did not see themselves as being on the same team with the health professionals working for health promotion in their communities.

A good example of this lack of appreciation for the overarching common interests among lawyers, health care providers, and public health practitioners as professionals, with the potential for collectively leveraging their respective professional strengths for the promotion of health, is the author's own experience attempting to set up a medical-legal partnership ("MLP") in Atlanta in the 1980s and 1990s. Today, MLPs are well accepted, ${ }^{34}$ and the Atlanta MLP, known as the Health Law Partnership ("HeLP"), has been in operation successfully since $2004 .{ }^{35}$ Yet, it took

32 See Sage, supra note 1; Elizabeth Tobin Tyler, Allies Not Adversaries: Teaching Collaboration to the Next Generation of Doctors and Lawyers to Address Social Inequality, $11 \mathrm{~J}$. HeAlth CARE L. \& POL'Y 249, 249-50 (2008).

33 The CDC created the Public Health Law Program in 2000. See Public Health Law Program: About Us, CTRS. FOR DISEASE CONTROL \& PREVENTION, http://www.cdc.gov [https://perma.cc/EE27-ATLN] (last updated Dec. 17, 2013). RWJF has invested considerable resources in two public law initiatives over the last decade; see THE NETWORK FOR PUB. HEALTH L., https://www.networkforphl.org/ [https://perma.cc/GQT5-LYGS] (last visited September 16, 2016); see PUB. HEALTH L. RES. PROGRAM, http://publichealthlawresearch.org/ [https://perma.cc/M8BP-5Y7S] (last visited September 16, 2016).

34 See infra notes 154-155 and accompanying text (discussing MLPs generally).

${ }^{35}$ Our MLP, the Health Law Partnership ("HeLP"), is a collaboration of the Atlanta Legal Aid Society, Children's Healthcare of Atlanta, and the Georgia State University College of Law. It was awarded the Outstanding Medical-Legal Partnership award by the National Center for Medical Legal Partnership in 2014 in its tenth anniversary year. HeLP Receives Outstanding MLP Award, GA. ST. U. C. OF L. (July 3, 2014), http://law.gsu.edu [https://perma.cc/AG83-G293]. For a discussion of HeLP's history, see Robert Pettignano et al., The Health Law Partnership: A Medical-Legal Partnership Strategically Designed to Provide a Coordinated Approach to Public Health Legal Services, Education, Advocacy, Evaluation, Research, and Scholarship, 35 J. OF 
over fifteen years of persistent effort to find a local hospital willing to collaborate with local legal aid attorneys in Atlanta to provide free legal services to their low-income patients and to collaborate with the Georgia State law school to allow law students to work with these attorneys. HeLP now successfully provides a broad range of what it calls "public health legal services" that address the social and economic determinants of health. ${ }^{36}$

As MLP pioneers, I and my partners at the Atlanta Legal Aid Society and Georgia State Law could only project a vision of what our interprofessional collaboration might look like, as we did not then have the social proof of widespread acceptance by others that makes it easier to set up an MLP today. The hospital personnel we approached in those early years were suspicious: would the lawyers and law students simply be trolling for potential malpractice clients? With only an image of lawyers as "ambulance-chasers" and of law as a malpractice threat held over the heads of health care providers, a succession of hospital administrators and doctors could not be persuaded that we genuinely thought we could help improve the health of their low-income patients. In these early MLP days, many health professionals did not appreciate how their patients' health could be improved by collaborating with lawyers to addressing the social, economic, and environmental challenges that were exacerbating their patients' health conditions, including unsafe housing, unemployment and lack of adequate financial resources, family instability, food insecurity, and unaccommodated special education needs.

For their part, the lawyers had a similarly narrow lens for understanding what an interprofessional collaboration might look like. Some at the legal aid society thought all they needed was a desk in an office near the hospital to open up shop and take more legal aid clients. They did not perceive their role as requiring a peer presence on the floor of the hospital itself to work directly with the health care professionals as a team. Yet this proximity to health professionals on the hospital premises was an indispensable, interdisciplinary component of HeLP to enable it to be able to provide a more holistic set of services for patients that might improve and stabilize their health and forestall their return through the revolving doors of the emergency room. At first, the lawyers also raised professionalism concerns that foregoing the possibility of suing a collaborating hospital would be an unethical constraint on their legal representation of clients. For its part, our law school's administration told me that it simply did not "get what all this interdisciplinary stuff of yours, Charity, gets for the law school."

Even David M. Satcher, former Assistant Secretary for Health and Surgeon General under former President Bill Clinton, one of the country's most distinguished public health advocates, initially had trouble envisioning a role for lawyers in addressing health disparities. As a long-time, passionate public health champion for health equity, he often spoke and wrote publicly about

Legal Med. 57, 57-79 (2014); see also Health Law Partnership (HeLP), HEALTHLAwPARTNERSHIP.ORG, https://healthlawpartnership.org/ [https://perma.cc/29U7-8J7S] (last visited September 16, 2016). Today, MLPs have been legislatively endorsed in Georgia. GA. Code Ann. § 31-2-4d (11) (A)-(D) (2014).

36 Health Law Partnership ("HeLP"), Mission, HEALTH LAW PARTNERSHIP https://healthlawpartnership.org/ [https://perma.cc/8BWD-XHWC] (last visited Dec. 16, 2016) (discussing HeLP's mission to provide "public health legal services."). 
getting the whole community involved in addressing health disparities. ${ }^{37}$ Despite his broadminded and inclusive vision for the community that needed to come together to promote health equity, he omitted lawyers from mention in that community, reflecting their absence generally among public health advocates in the past. For example, in a 1998 letter to the editor of Ebony magazine, he cited, with approval, President Clinton's efforts to increase funding to combat health disparities, and then said, "[b]ut money is not enough to solve this problem. We envision an active role for churches, fraternities and sororities, business leaders, and elected and appointed officials, and ordinary citizens in this fight to build a better, healthier future for all Americans." 38

In the mid-2000s, the author had the privilege to hear Mr. Satcher speak eloquently at the Morehouse School of Medicine, where he has established the Satcher Health Leadership Institute, on society's continuing challenge to eliminate health disparities. He similarly enumerated the range of community members who could play a role in eliminating health disparities. When I asked him afterward why he had not mentioned lawyers as well, he responded, “I guess I haven't really thought about them as having a role." 39

\section{THE PRESENT}

\section{A. Progress on the IOM's Recommendations to Address Health Care Disparities}

Key private and public stakeholders, including health care providers and federal and state government agencies, have heeded the findings and sweeping recommendations of the IOM's Unequal Treatment report. ${ }^{40}$ While much of their focus today remains on addressing disparities in health care (rather than addressing the social determinants of health), these stakeholders have clearly acknowledged the serious problem of health disparities and that something needs to be done about it, and they are taking organizational steps to address it.

In particular, the federal Patient Protection and Affordable Care Act ${ }^{41}$ ("ACA") has numerous provisions aimed at reducing health disparities in health care access, delivery, and organizational infrastructure. These provisions are responsive to a number of IOM recommendations, including expanding health care coverage through public and private health insurance, increasing health care workforce diversity, improving the cultural competency of health care providers, enhancing data

37 See generally Morehouse School of Medicine, About David Satcher, http://www.msm.edu [https://perma.cc/BJ3S-NSLD] (last visited December 16, 2016) (providing extensive list of publications related to health equity and health disparities).

${ }^{38}$ David Satcher, Letter to the Editor, The 10 Biggest Killers of Blacks, EBONY, June 1998, at 10-12, https://books.google.com/books [https://perma.cc/U7CS-P9BM].

${ }^{39}$ Postscript: I am proud to say that the first lawyer to secure a fellowship (2012-2013) in the Satcher Institute's prestigious Health Policy Leadership Fellowship Program was a graduate of our law school, Megan Douglas, whose persuasively-made case that lawyers should have a place at the community table for addressing health disparities was generously accepted. See Spotlight: Examining the Impact of Law and Policy on Health Outcomes, GA. ST. U. C. L. CTR. FOR L., HEALTH \& SOC'Y (May 10, 2013), http://clhs.law.gsu.edu [https://perma.cc/7W9P-T6S3].

${ }^{40}$ See supra notes 23-26 and accompanying text (identifying key recommendations of IOM report).

${ }^{41}$ Patient Protection and Affordable Care Act, Pub. L. 111-148, 124 Stat. 119 (2010). 
collection and monitoring, and increasing research devoted to health disparities. ${ }^{42}$ In addition, the ACA provides stronger antidiscrimination provisions than under Title VI. ${ }^{43}$

The IOM recommendation to increase awareness of racial and ethnic disparities in health care among the general public, key stakeholders, and health care providers is reflected in the significantly greater attention that the federal government has given to health equity since the ACAs passage in 2010. Before then, HHS had established an Office of Minority Health, ${ }^{44}$ which was a significant outcome of the Heckler Report, ${ }^{45}$ as had the National Institutes of Health. ${ }^{46}$ The ACA required the establishment of Offices of Minority Health within six HHS agencies: ${ }^{47}$ the Agency for Healthcare Research and Quality ("AHRQ"), ${ }^{48}$ the Centers for Disease Control and

42 Inst. of Med., Achieving Health Equity Via the Affordable Care Act: Promises, PROVISIONS, AND MAKING REFORM A REALITY FOR DiVERSE PATIENTS: WORKSHOP SUMMARY 516 (Karen M. Anderson \& Steve Olson, Rapporteurs, The Nat'l Academies Press, 2015), https://www.nap.edu [https://perma.cc/FUB4-A99V]; Rene Bowser, The Affordable Care Act and Beyond: Opportunities for Advancing Health Equity and Social Justice, 10 HASTINGS RACE \& PoverTy L.J. 69, 95-112 (2013); Daryll C. Dykes, Evidence, Social Psychology, and Health Care: Health Injustice and Justice in Health: The Role of Law and Public Policy in Generating, Perpetuating, and Responding to Racial and Ethnic Health Disparities Before and After the Affordable Care Act, 41 WM. Mitchell L. REV. 1129, 1194-2010 (2015); Stephen B. Thomas et al., Less Talk, More Action: Accelerating Innovative Strategies to Eliminate Racial and Ethnic Disparities, 55 How. L.J. 705, 718-21 (2012).

43 Watson, supra note 31, at 859 (observing that "Section 1557's [of the ACA] antidiscrimination mandate reaches many more health insurance, health care, and public health activities" than Title VI).

${ }^{44}$ About the Office of Minority Health, U.S. DeP'T of HeAlth \& Hum. SERvs. OfF. OF MINORITY HEALTH, http://minorityhealth.hhs.gov [https://perma.cc/M5NB-FALD] (last updated Jan. 5, 2016) (The HHS Office of Minority Health includes the Office of Minority Health Resource Center; see Office of Minority Health Resource Center, U.S. DeP'T OF HeAlth \& HuM. SERVs. OFF. OF MINORITY HEALTH, http://minorityhealth.hhs.gov [https://perma.cc/VX49-4CHH] (last updated July 20, 2016).

${ }^{45}$ Offices of Minority Health at HHS: HHS Office of Minority Health and Establishment of Federal Offices of Minority Health, CTRS. FOR MEDICARE \& MEDICAID SERVs., https://www.cms.gov [https://perma.cc/Q8Z7-MMX2] (last visited May 7, 2016).

46 About NIMHD, NAT'L Insts. ON MinORITY HEAlth AND HEAlTh Disparities, http://www.nimhd.nih.gov [https://perma.cc/6W67-6D6H] (last visited May 7, 2016).

${ }^{47}$ HHS Agency Offices of Minority Health, CTRS. FOr Disease CONTROL \& Prevention, http://www.cdc.gov [https://perma.cc/466A-TZMV] (last updated Jan. 15, 2016).

48 AHRQ's National Healthcare Quality \& Disparities Report Program falls under AHRQ's Center for Quality Improvement and Patient Safety. Center for Quality Improvement and Patient Safety (CQuIPS), AGENCY FOR HEALTHCARE RES. AND QUALITY (“AHRQ”), http://www.ahrq.gov [https://perma.cc/A37F-E929] (last updated Dec. 2015); see also National Healthcare Quality \& Disparities Reports, AgENCY FOR HEALThCARE RES. AND QUALITY ("AHRQ"), http://www.ahrq.gov [https://perma.cc/7ECN-QMT7] (last updated July 2016). Prior to the ACA, AHRQ had established a minority health office administratively and has elected to retain its current reporting structure under the ACA; see Offices of Minority Health at HHS, U.S. DEP'T OF HEALTH 
Prevention ("CDC"), ${ }^{49}$ the Centers for Medicare and Medicaid Services, ${ }^{50}$ the Food and Drug Administration, ${ }^{51}$ the Health Resources and Services Administration, ${ }^{52}$ and the Substance Abuse and Mental Health Services Administration. ${ }^{53}$ At the state level, there are offices for minority health in all fifty states today. ${ }^{54}$

One of the four overarching goals of Healthy People 2020, a collaborative initiative among numerous federal agencies and other stakeholders to set ten-year health goals and objectives for the country, is expressly to "achieve health equity, eliminate disparities, and improve the health of all groups." 55 The National Partnership for Action to End Health Disparities ("NPA"), a federal multi-agency collaboration to address health equity, has produced a consensus "National Stakeholder Strategy for Achieving Health Equity" ("NPA Stakeholder Strategy") which provides a common set of goals and objectives for public and private sector initiatives to eliminate health disparities. ${ }^{56}$ The HHS Office of Minority Health simultaneously developed an "Action Plan to Reduce Racial and Ethnic Health Disparities" ("HHS Disparities Action Plan"), which

\& HumAN SERVs. OFFICE OF MinORITY HEALTH, http://minorityhealth.hhs.gov [https://perma.cc/LZW3-YRPA] (last updated Oct. 29, 2015). AHRQ has priority populations that must be included in its research efforts and that are often the populations at risk for health disparities, including women, children, racial and ethnic minorities, populations with special health care needs (chronic illness, disabilities, and end of life care needs), the elderly, low-income, innercity, and rural populations); see Priority Populations, AGENCY FOR HEALTHCARE RES. AND QUALITY (“AHRQ”), http://www.ahrq.gov [https://perma.cc/SS6R-24SZ] (last updated April 2016).

${ }^{49}$ About CDC's Office of Minority Health \& Health Equity (“OMHHE”), CTRS. FOR DiSEASE CONTROL \& PREVENTION http://www.cdc.gov [https://perma.cc/Y77B-5TGN] (last updated Aug. 12, 2015) (CDC had previously established an office of minority health before the ACA; see Offices of Minority Health at HHS, supra note 45).

50 About CMS Office of Minority Health, CTRS. FOR MEDICARE \& MEDICAID SERVS., https://www.cms.gov [https://perma.cc/Q8BN-KSVF] (last visited Sept. 23, 2016).

${ }^{51}$ Minority Health, U.S. FoOD \& DRUG ADMIN. http://www.fda.gov [https://perma.cc/P9MX5Z94] (last updated Aug. 29, 2016).

52 Office of Health Equity, Health Resources AND Servs. Admin., http://www.hrsa.gov [https://perma.cc/F8QM-PT5Q] (last updated June 2016).

53 Behavioral Health Equity, Substance Abuse and Mental Health Servs. Admin., http://www.samhsa.gov [https://perma.cc/UBH3-YEPQ] (last updated Jan. 7, 2016).

${ }^{54}$ State Offices of Minority Health and Related State Information, NAT'L PARTNERSHIP FOR ACTION TO END HEALTH DISPARITIES, http://minorityhealth.hhs.gov [https://perma.cc/A6THLCTD] (last updated May 17, 2016).

55 U.S. Dep't of Health and Human Servs., Healthy People 2020 Framework: The Vision, Mission, and Goals of Healthy People 2020, HEALTHYPEOPLE.GOV https://www.healthypeople.gov [https://perma.cc/3YTG-DFH6] (last visited September 16, 2016).

${ }^{56}$ National Stakeholder Strategy for Achieving Health Equity, NATIONAL PARTNERSHIP FOR ACTION TO END HEALTH DisPaRitiES (Mar. 25, 2015, 12:00 AM), http://minorityhealth.hhs.gov [https://perma.cc/765T-VRBC] [hereinafter NPA Stakeholder Strategy]. 
complements the NPA Stakeholder Strategy. ${ }^{57}$ Collectively, these two documents are intended to provide visible and accountable federal leadership on reducing health disparities and to promote effective collaborations among public and private stakeholders. ${ }^{58}$

The nonprofit sector has also made substantial efforts to increase public awareness of health disparities. The Robert Wood Johnson Foundation ("RWJF") has taken a significant leadership role in challenging the country to work towards health equity and has devoted significant resources and research efforts toward that end. ${ }^{59}$ With achieving health equity at its core, the Foundation's vision for building a "culture of health" in this country aims to enable all people to live healthier lives. ${ }^{60}$ Other major non-profit organizations have also undertaken significant efforts to try to raise awareness about and address health disparities. ${ }^{61}$ Philanthropic funders and community

${ }^{57}$ HHS Disparities Action Plan to Reduce Racial and Ethnic Health Disparities: A Nation Free of Disparities in Health and Health Care, U.S. DeP'T OF HeAlth AND Human SERvs. OfF. OF MINORITY HEALTH, http://www.minorityhealth.hhs.gov [https://perma.cc/NNV6-QZNA] (last visited May 7, 2016) [hereinafter HHS Disparities Action Plan]; see also HHS Action Plan to Reduce Racial and Ethnic Health Disparities: Implementation Progress Report 2011-2014, U.S. Dep'T of Health AND Human Servs. OfF. OF Minority Health (Nov. 2015), http://www.minorityhealth.hhs.gov [https://perma.cc/JX3S-KGUD] [hereinafter HHS Disparities Action Plan Progress Report].

${ }^{58}$ NPA National Stakeholder Strategy, supra note 56, at 1; HHS Disparities Action Plan, supra note 57, at 1 (stating that the "[H]HS Disparities Action Plan and the NPA Stakeholder Strategy can be used together to coordinate action that will effectively address racial and ethnic health disparities across the country. Furthermore, the HHS Disparities Action Plan builds on national health disparities' goals and objectives recently unveiled in Healthy People 2020, and leverages key provisions of the Affordable Care Act and other cutting-edge HHS initiatives").

59 Grants and Grant Programs, ROBERT WOOD JOHNSON Found, http://www.rwjf.org/ [https://perma.cc/TNE6-8HRL], (last visited December 18, 2016) (RWJF funds "program and policy initiatives in four areas which are each critical to health equity": health systems; healthy kids, healthy weight; healthy communities, and health leadership).

60 How We Work: Building a Culture of Health, ROBERT WOOD JOHNSON Found., http://www.rwjf.org [https://perma.cc/E46F-W8UN] (last visited September 17, 2016); see also What Shapes Health? Closing Socioeconomic Gaps in Health, RWJF COMMISSION TO BUILD A HEALTHIER AM., http://www.rwjf.org [https://perma.cc/J4BT-9KAW] (last visited September 17, 2016) (collecting reports, recommendations, and other resources for strategies to prioritize investments in the physical and mental well-being of young children, create communities that foster health-promoting behaviors, and broaden health care to promote health outside of the medical system).

61 See, e.g., Health Equity, AM. PuB. HeAlth Ass'N, http://www.apha.org [https://perma.cc/BTG7-U89A] (last visited September 17, 2016); see also Disparities Policy, HENRY J. KAISER FAMILY FOUND., http://kff.org/disparities-policy/ [https://perma.cc/5VC8TC2N] (last visited September 16, 2016); see also Research Network on SES \& Health, JOHN D. AND Katherine T. MacARthur Found.: U. of CAL., SAN Francisco, http://www.macses.ucsf.edu/ [https://perma.cc/N3SS-Q8RY] (last visited September 16, 2016); see also Racial Equity, W. K. KeLloGg Foundation, https://www.wkkf.org/what-we-do/racialequity (last visited September 16, 2016). 
organizations are beginning to use a health equity lens for grant making and partnerships. ${ }^{62}$ The American Hospital Association has provided a framework for hospitals to guide their institutional strategies for eliminating health care disparities. ${ }^{63}$ Unnatural Causes: Is Inequality Making Us Sick, is an award-winning, seven-part documentary exploring racial and socioeconomic disparities that was aired by PBS in 2008 and that helped to raise public consciousness and understanding about them. ${ }^{64}$

The ACA has responded to the IOM's recommendation for more cross-cultural education to improve health care professionals' ability to provide quality care to diverse patient populations. It did so by providing financial incentives (e.g., scholarships and loan repayment programs) for diversifying the health care workforce by attracting minority students to the health care professions and attracting minority professionals to underserved communities. ${ }^{65}$ The ACA also calls for the promotion of cultural competency training of health care professionals. ${ }^{66}$ The HHS Disparities Action Plan and the NPA Stakeholder Strategy also include goals to improve the diversity and cultural competence of the health-related workforce. ${ }^{67}$ Many state laws reflect parallel efforts to diversify the health care workforce and improve their cultural competency. ${ }^{68}$ The Joint Commission, which is the national accrediting body for U.S. hospitals, has also provided guidance for advancing the cultural competence of health care providers. ${ }^{69}$

With respect to the IOM's recommendation for more data collection and monitoring of progress toward eliminating health disparities, a number of federal agencies have been engaging in significant efforts to collect data on health disparities. Since 2003, AHRQ has annually published a National Healthcare Quality and Disparities Report. ${ }^{70}$ The CDC has issued three

62 Faith Mitchell, Innovations in Health Equity and Health Philanthropy, STAN. Soc. INNOVATION REV. sponsored by GRANTMAKERS IN HEALTH, 1, 3-4 (Spring 2016), http://ssir.org [https://perma.cc/U7RF-RFJL] (reviewing examples of strategies to promote health equity through organizing and advocacy, grant making, research and data collection, cross-sectoral collaboration and community engagement).

${ }^{63}$ Equity of Care: Toolkit for Eliminating Health Care Disparities, HosPS. IN PURSUIT OF EXCELLENCE (Jan. 2015), http://www.hpoe.org [https://perma.cc/2D83-RRY6].

64 California Newsreel, Unnatural Causes: Is Inequality Making Us Sick?, UNNATURALCAUSES.ORG, http://www.unnaturalcauses.org/ (last visited September 17, 2016).

${ }^{65}$ Bowser, supra note 42, at 99-101, 108-09; Dykes, supra note 42, at 1200-01.

${ }^{66}$ Dykes, supra note 42, at 1201.

${ }^{67}$ HHS Disparities Action Plan, supra note 57, at 15-19; NPA Stakeholder Strategy, supra note 56 , at 127-31.

${ }^{68}$ Health Disparities: State Laws, NAT'L Conf. OF St. LegiSlatures, (Jan. 20, 2014), http://www.ncsl.org [https://perma.cc/66UW-QB66].

69 See generally The JoInt COMM'N, Advancing EfFective COMMUniCATiOn, Cultural Competence, and PATIENT-And FAmily-Centered CARE: A RoAdmap For Hospitals (2010), http://www.jointcommission.org [https://perma.cc/7GMG-W8HP].

70 Agency for HeAlthCARE RESEARCh AND QuAlity (“AHRQ”), 2014 NATiOnAL HEALTHCARE QUALITY \& DisPaRITIES REPORT (2014), http://www.ahrq.gov [https://perma.cc/U2LS-Y3KC] [hereinafter AHRQ DISPARITIES REPORT]. 
reports on health disparities and inequalities that complement the annual AHRQ reports. ${ }^{71}$ At the state level, many states have passed laws authorizing new study commissions, task forces, and other organizational entities to collect data on health disparities within the state and make recommendations for efforts to address them. ${ }^{72}$

With respect to the IOM's recommendation for more research on the sources of health disparities, promising interventions, and barriers to eliminating disparities, a virtual explosion in research and scientific and scholarly publications has occurred in the past decade on these topics, as discussed in the next section.

\section{B. Shift in Mindset: The Socioeconomic Determinants of Health}

While the Heckler and IOM reports focused on discrimination or bias by health care providers as key contributors to health disparities, little evidence shows that the provision of health care reduces disparities in health outcomes. ${ }^{73}$ Research has shown that lack of access to medical care does not necessarily account for disparities in life expectancies. ${ }^{74}$ More broadly, health care has a

${ }^{71}$ Ctrs. For Disease Control \& Prevention, CDC Health Disparities \& Inequalities RePort-United States (2013), Mortality and Morbidity Weekly Report, vol. 62, no. 3 (Supp.) (November 22, 2013), https://www.cdc.gov/ [https://perma.cc/MU4A-2M7T] (last visited December 18, 2016) [hereinafter CDC HEALTH DiSPARITIES 2013 REPORT]; CTRS. FOR DisEASE Control \& Prevention, CDC Health Disparities \& Inequalities Report-United States (2011), Mortality and Morbidity Weekly Report, vol. 60 (Supp.) (January 14, 2011), https://www.cdc.gov/ [https://perma.cc/CXY4-S7DQ] (last visited December 18, 2016); CTRS FOR Disease Control and Prevention, Health, United States, 2015: With Special Feature on RACIAL AND ETHNIC HEALTH DisPaRITIES (2016), http://www.cdc.gov [https://perma.cc/BD9RPBMH].

72 Health Disparities: State Laws, supra note 68; see also Jessica L. Young et al., Review of State Legislative Approaches to Eliminating Racial and Ethnic Health Disparities, 2002-2011, 105 AM. J. OF PUB. HEALTH S388, S391 (2015) http://ajph.aphapublications.org [https://perma.cc/N864-GKBA] (noting that "states were likely to approach eliminating racial/ethnic health disparities by developing governmental infrastructure (e.g., minority health or health disparities agencies and statewide and local task forces), providing appropriations, and focusing on specific diseases and data collection").

${ }^{73}$ Lisa Berkman \& Arnold M. Epstein, Beyond Health Care-Socioeconomic Status and Health, 358 NEW ENG. J. MED. 2509-10, $2510 \quad$ (2008), http://www.nejm.org [https://perma.cc/CT8P-QQBW] (observing that "In the United States we have very few examples of health care interventions that have reduced disparities in health care, not to mention health ... $[\mathrm{P}]$ olicies related to preventive social, economic, and behavioral interventions might well have a greater effect on reducing disparities than traditional medical interventions, even if as an unintended by-product . . . Although national health coverage is important for many reasons, we should not count on it to reduce more than a small part of the socioeconomic, racial, and ethnic disparities we see in the United States").

${ }^{74}$ Raj Chetty et al., The Association Between Income and Life Expectancy in the United States, 2001-2014, 315 J. OF THE AM. MED. ASS'N 1750, 1763 (2016) http://jama.jamanetwork.com [https://perma.cc/U9ZJ-RWD9] (finding that "[1]ife expectancy for low-income individuals was 
smaller percentage of impact on a person's health than other factors, such as the person's healthrelated behaviors (e.g., smoking, alcohol consumption, and nutrition), housing and residential environments, education, employment and working conditions, and income. ${ }^{75}$ Indeed, scholars have proposed that social and environmental conditions are the "fundamental causes" of health disparities and that solely addressing health care-related risk factors are not likely to be successful in reducing health disparities. ${ }^{76}$

While the Heckler and IOM reports focused on racial and ethnic disparities in health and healthcare access and delivery, more recently "a growing body of evidence shows that race and ethnicity are not nearly as important in explaining health disparities as are underlying factors such

not significantly correlated with measure of the quantity and quality of medical care provided, such as the fraction insured and measures of preventive care . . . [A] lack of access to care is not the primary reason that lower income individuals have shorter life expectancies").

75 Our Approach, County Health Rankings And RoAdmaps, U. Wis. POPUlation Health INST. AND RWJF, http://www.countyhealthrankings.org [https://perma.cc/75AP-9GK2] (last visited May 7, 2016) (estimating the percentages of contribution to health of four factors: health behaviors $(30 \%)$, clinical care $(20 \%)$, social and economic factors $(40 \%)$, and physical environment (10\%)); Elizabeth Docteur \& Robert A. Berenson, In Pursuit of Health Equity: Comparing U.S. and EU Approaches to Eliminating Disparities, ROBERT WOOD Found. \& URB. INST. 1, 2 (June 2014), http://www.rwjf.org [https://perma.cc/F3QF-BESS] (noting that "[r]esearchers estimated that improvements in health care access and quality offered the potential to reduce preventable mortality by only as little as 10-15 percent"); The Relative Contribution of Multiple Determinants to Health Outcomes, Health AfF. (Aug. 21, 2014), http://www.healthaffairs.org [https://perma.cc/UPH9-MEZB] (citing experts who estimate 10$20 \%$ contribution of medical care to health); J. Michael McGinnis et al., The Case for More Active Policy Attention to Health Promotion, 21 HeAlTh AfF. 78, (2002), (estimating the respective contributions to early deaths: genetic predispositions, $30 \%$; social circumstances, $15 \%$; environmental exposures, 5\%; behavioral patterns, 40\%; and shortfalls in medical care, 10\%); J. Michael McGinnis \& William H. Foege, Actual Causes of Death in the United States, 270 J. AM. MED. ASS'N. 2207, 2210 (1993), http://jama.jamanetwork.com [https://perma.cc/4D6N-AV7A]) (stating that the "Carter Center project estimated that gaps in primary care, as indicated by lack of access to standard primary care, screening, and preventive interventions, accounted for $7 \%$ of premature deaths"); Steven H. Woolf \& Jason Q. Purnell, The Good Life: Working Together to Promote Opportunity and Improve Population health and Well-being, 315 J. OF THE AM. MED. ASS'N 1706 (2016), http://jama.jamanetwork.com [https://perma.cc/UR9G-RXBW] (observing that "[h]ealth is about more than health care, with health care accounting for only an estimated $10 \%$ to $20 \%$ of health outcomes").

76 S. Jay Olshansky et al., Differences In Life Expectancy Due To Race And Educational Differences Are Widening, And Many May Not Catch Up, 31 Health AfF. 1803, 1804 (Aug. 2012), http://content.healthaffairs.org [https://perma.cc/33BT-Z5WC]; see also Paula Braveman \& Laura Gottlieb, The Social Determinants of Health: It's Time to Consider the Causes of the Causes, 129 PuB. HeAlth R. 19 (2014), http://www.ncbi.nlm.nih.gov [https://perma.cc/5484TJZW] (reviewing evidence that points to "socioeconomic factors such as income, wealth and education as the fundamental causes of a wide range of health outcomes"). 
as socioeconomic status, place of residence, and living conditions." those landmark reports, the focus of this rapidly growing literature has shifted to encompass the broader role of a variety of social, economic, and environmental determinants of health. ${ }^{78}$ Research in recent decades has confirmed that health is not predominantly a matter of individual genetics or

${ }^{77}$ Docteur \& Berenson, supra note 75 , at 4.

78 See, e.g., Donald Acheson, Dep'T of Health, Inequalities in HeAlth: Report of AN INDEPENDENT INQUIRY, 8 (1998), https://www.gov.uk [https://perma.cc/257D-7TS7] (finding that the "weight of scientific evidence supports a socioeconomic explanation of health inequalities ... We have identified a range of areas for future policy development, judged on the scale of their potential impact on health inequalities, and the weight of evidence. These areas include: poverty, income, tax benefits; education; employment; housing and environment; mobility, transport and pollution; and nutrition;" out of 39 different health policy recommendations in the report aimed at improving population health, only the last three were based on traditional health care access and; World Health Org. Comm'n on Social Determinants of Health, Closing the Gap in A Generation: Health Equity Through action on The Social Determinants of Health FINAL REPORT iii (2008), http://www.who.int [https://perma.cc/7NEH-9NCG] (stating that "[t]hese inequities in health, avoidable health inequalities, arise because of the circumstances in which people grow, live, work, and age, and the systems put in place to deal with illness. The conditions in which people live and die are, in turn, shaped by political, social, and economic forces."); NAT'L ASS'N CNTy. \& City Health Officials, Tackling Health Inequities Through Public Health Practice: A HandBook for ACtion 12 (Richard Hofrichter, ed., 2006) http://archived.naccho.org [https://perma.cc/Y47U-422B] (finding that "[p] population health outcomes are primarily the result of social and political forces, not lifestyles or behavior . . . An accumulation of negative social conditions and lack of fundamental resources contribute to health inequities, and include economic and social insecurity, racial and gender inequality, lack of participation and influence in society, unfavorable conditions during childhood, absence of quality and affordable housing, unhealthy conditions in the workplace and lack of control over the work process, toxic environments, and inequitable distribution of public goods"); MICHAEL MARMOT, The Status Syndrome: How Social Standing Affects our Health and Longevity 1-2 (2004), (developing book's thesis based on 25 years of research that "[w]here you stand in the social hierarchy is intimately related to your chances of getting ill, and your length of life ... The remarkable finding is that among all of these people, the higher the status in the pecking order, the healthier they are likely to be. In other words, health follows a social gradient. I call this the status syndrome ... It is inequality in these [how much control you have over life and your opportunity for full social engagement and participating] that plays a big part in producing the social gradient in health. Degrees of control and participation underlie the status syndrome"); WORLD HEALTH Organization, Social Determinants of Health: The Solid Facts 5, (Richard Wilkinson \& Michael Marmot, eds., $2^{\text {nd }}$ ed. 2003) http://www.euro.who.int [https://perma.cc/36P9-QYVL] (reviewing how various social and economic conditions are associated with health outcomes, including socioeconomic status; psychosocial stresses; early maternal-child health interventions and education; social exclusion; amount of control in work environment; unemployment; social support and networks; addiction to alcohol, drugs, and tobacco; food and nutrition; and physical activity and transportation alternatives). 
access to health care, but rather health and health inequities are linked to underlying social, economic, and environmental determinants of health. ${ }^{79}$

For example, research has shown that disparities in health status persist by educational attainment and income. A recent study on the relationship between income and life expectancy confirmed that higher income was associated with greater longevity ${ }^{80}$ In this study of mortality data between 2001 and 2014 in the United States, researchers found that life expectancy at age forty increases continuously with income percentile, and that the wealthiest one percent of the population has a life expectancy that is fifteen years (for men) to ten years (for women) longer than the poorest one percent (see Figure 2). ${ }^{81}$
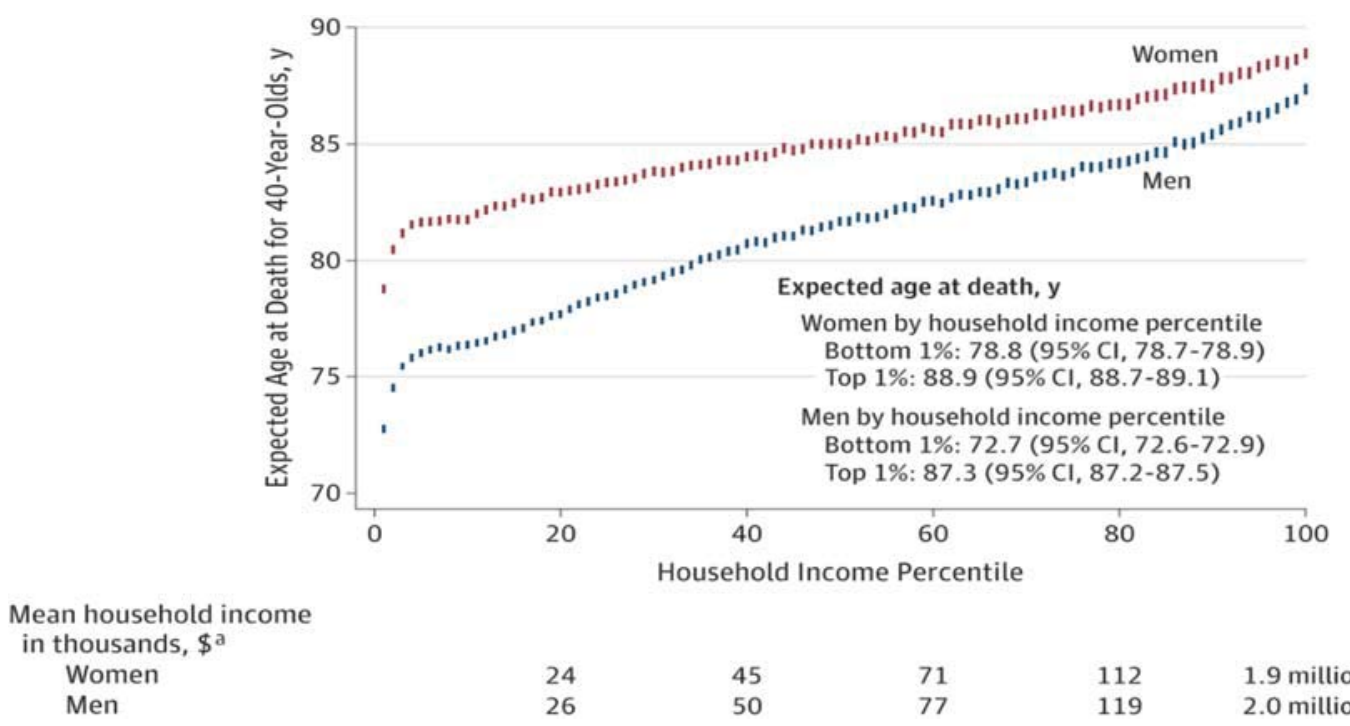

$\begin{array}{lllll}24 & 45 & 71 & 112 & 1.9 \text { million } \\ 26 & 50 & 77 & 119 & 2.0 \text { million }\end{array}$

Figure 2. Race and Ethnicity-Adjusted Life Expectancy for 40-Year-Olds by Household Income Percentile, 2001-2014. ${ }^{82}$

A Nobel prize-winning editorial writer commented on this study:

Not only does the top $1 \%$ of the income distribution live longer than everyone else, but the gap in life expectancy at 40 years of age is widening, and there has been little gain in life expectancy among the lowest income individuals living in the United States. The infamous $1 \%$ is not only richer, but much healthier. ${ }^{83}$

${ }^{79}$ Robert Wood Johnson Found. COMM’n to Build A HeAlthier AmericA, Time to ACt:

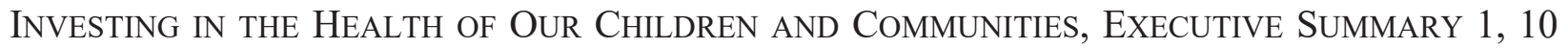
(2014), http://www.rwjf.org [https://perma.cc/R785-TKL9].

${ }^{80}$ Chetty et al., supra note 74 , at 1750 .

${ }^{81} \mathrm{Id}$. at 1762.

${ }^{82}$ Chetty et al., supra note 74, at 1754.

${ }^{83}$ Angus Deaton, On Death and Money: History, Facts, and Explanations, 315 J. OF THE AM. MED. ASS'N 1703, 1703 (2016), http://jama.jamanetwork.com [https://perma.cc/C2SJ-L4PK]. 
Studies have long demonstrated this almost lock-step association between income and life expectancy, with a gradient along each increasing percentile of income distribution reflecting increasing longevity and improved health. ${ }^{84}$

Researchers have also documented a similar association between higher educational attainment, greater longevity, and better health (see Figure 3). ${ }^{85}$ While the exact causal connection between health and education continues to be debated, ${ }^{86}$ researchers have suggested that a number of community characteristics-such as "food access, spaces and facilities for physical activity, access to health care, community economic resources, crime and violence, and environmental

${ }^{84}$ Comm. on Population-Phase II, The Nat'l Acads. of Scis., Eng'G, \& Med., The GROWING GAP IN LIFE EXPECTANCY BY INCOME: IMPLICATIONS FOR FEDERAL PROGRAMS AND POLICY RESPONSES 2, 11-12 (2015), http://www.nap.edu [https://perma.cc/LD9B-5V8Q] (confirming "numerous other studies showing that the gradient in life expectancy by income has been increasing over time ... It has long been the case that better-educated, higher-income enjoy longer life expectancies than less-educated, lower-income people . . Over the past several decades, however, a number of studies have found that the gradient in life expectancy by education and income has become steeper: the gap in life expectancy between the top and bottom has become larger").

${ }^{85} \mathrm{Id}$. at 40-42 (surveying studies that have found "that mortality differentials by educational attainment have been widening in recent decades"); see also John Bound et al., Measuring Recent Apparent Declines in Longevity: The Role of Increasing Educational Attainment, 34 HEALTH AfF. 2167, 2169, 2172 (2015) (finding "clear evidence of increasing inequality of survival probabilities between those at the bottom and those at the top of the educational distribution" and concluding that "the entrenchment or even growth of other race-sex socioeconomic inequalities in longevity appear to signal chronic and insidious processes"); Olshansky et al., supra note 76, at 1803 (finding that "[i]n 2008 white US men and women with 16 years or more of schooling had life expectancies far greater than black Americans with fewer than 12 years of education-14.2 years more for white men than black men, and 10.3 years more for white women than black women"); Mitchell D. Wong et al., Contribution of Major Diseases to Disparities in Mortality, 347 New ENG. J. MED. 1585, 1586-87 (2002) (finding that "[w]hen adjusted for age, sex, and race, the number of potential life-years lost from all causes of death was 3.5 times as great for persons with less education than for persons with more education . . . Less-educated persons lost more potential life-years than more-educated persons for every specific cause we examined"); Emily B. Zimmerman et al., Understanding the Relationship Between Education and Health: A Review of the Evidence and an Examination of Community Perspectives, in Population Health: BeHaVioral and Social SCIENCE INSIGHTS 347, 348 (2015) http://www.healthpolicyohio.org [https://perma.cc/MRH9XRJX] (concluding that "[d]eath rates are declining among the most educated Americans, accompanied by steady or increasing death rates among the least educated").

${ }^{86}$ Jennifer Karas Montez \& Esther M. Friedman, Educational Attainment and Adult Health: Under What Conditions Is the Association Causal, 127 Soc. SCI. \& MED. 1, 1 (2015) (reviewing research papers in special journal issue addressing potential causal influences of education on health and observing that "educational attainment is often referred to as a "fundamental cause" of disparities in health and longevity"). 
exposure to toxins"-are linked to health outcomes and tend to vary with the educational level of the population. ${ }^{87}$

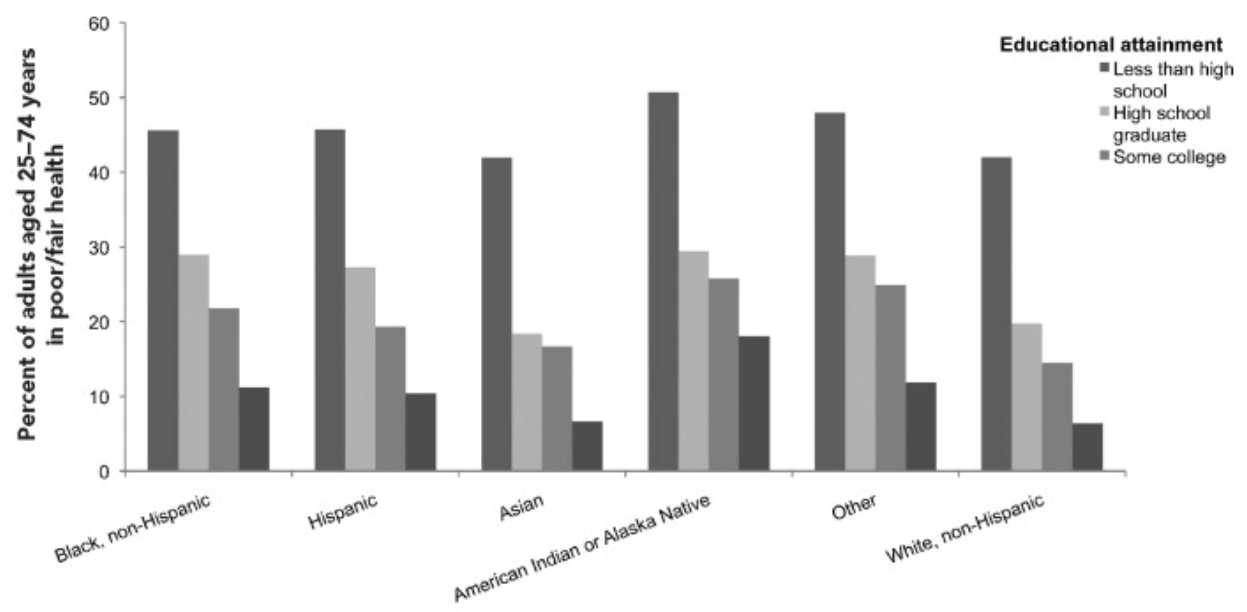

Figure 3. Socioeconomic Gradients in Poor/Fair Health among Adults Aged 25 to 74 Years within Racial/Ethnic Groups in the U.S., 2008-2010. ${ }^{88}$

Similarly, geographical and neighborhood differences are also associated with health disparities. Indeed, zip codes of residences are associated with significant differences in life expectancy. In New Orleans, for example, life expectancy can vary by as much as twenty-five years across neighborhoods. ${ }^{89}$ In Atlanta, a thirteen-year difference in life expectancy exists between the neighborhoods of Buckhead and Bankhead, less than six-miles apart. ${ }^{90}$ Place matters, the neighborhood where one lives and works are associated with better or worse health outcomes because the environmental and social conditions can vary significantly across different places:

[E]xtensive evidence documents the strong influence of the environment in which people live and work. One may desire to eat a healthy diet but find nutritious foods too costly or live too far from

87 Zimmerman et al., supra note 85, at 358-59; see also Mark D. Hayward et al., Trends and Group Differences in the Association between Educational Attainment and U.S. Adult Mortality: Implications for Understanding Education's Causal Influence, 127 SOC. SCI. \& MED. 8, 15 (2015) (positing a number of possible explanatory mechanisms for the strong association between education and health, including "psychosocial resources, valuable information and support for healthy lifestyles and quality medical care, social networks and relationships, greater cognitive skills, and a greater sense of control and human agency").

${ }^{88}$ Braveman and Gottlieb, supra note 76, at 25.

${ }^{89}$ Benjamin F. Evans et al., Social Determinants of Health and Crime in Post-Katrina Orleans Parish, in Place MAtTers TeChNical Reports 1, 23 (2012), http://www.societyhealth.vcu.edu [https://perma.cc/46PW-UYBV] (stating that "life expectancy at birth varies by 25.5 years between ZIP codes within Orleans Parish").

90 Maps to \#CloseHealthGaps; Life Expectancy Map: Atlanta, RoBERT WoOD JoHnSON FOUND., http://www.rwjf.org [https://perma.cc/J8F5-VVWP] (last visited May 7, 2016) (website provides maps of various cities showing large gaps in life expectancy depending on neighborhoods just miles apart). 
a supermarket that sells fresh produce. Parents might want to limit the time their children spend in front of a television or computer in favor of sending them outdoors for exercise, but their neighborhoods may be unsafe or lack playgrounds or sidewalks. The built environment-for example, the design of roads and pedestrian routes-can thwart efforts to walk or bicycle to the store or work. Poor and minority neighborhoods are often "'food deserts" with limited access to healthy foods but numerous fast-food outlets. Schools in low-income neighborhoods often serve inexpensive processed foods and rely on revenue from vending machine contracts that promote soft drinks and high-calorie snacks ... $[\mathrm{H}]$ ousing can expose occupants to lead and allergens. Bus depots, factories, highways, and hazardous waste sites are often situated near low-income and minority neighborhoods . . . Impoverished neighborhoods may have residents who are less able to help their neighbors. These neighborhoods may also have reduced social cohesion-which can influence health behavior; the sense of security and social well-being experienced by members of the community; and the ability of individuals within a community to join forces to advocate for needed services. ${ }^{91}$

Moreover, health outcomes are worse in rural counties than in urban ones. ${ }^{92}$ Even comparing different urban locales, one finds large variation in life expectancy. Low-income individuals, who live in cities with highly educated populations, high incomes, and high levels of government expenditures (like New York City and San Francisco) live longer than those in less affluent cities (like Detroit and Gary, Indiana). ${ }^{93}$

Such place-based determinants of health have become an increasing focus of research and policy proposals in recent years. ${ }^{94}$ Place matters for health, and it contributes to health disparities

${ }^{91}$ Steven H. Woolf \& Paula Braveman, Where Health Disparities Begin: The Role of Social and Economic Determinants-And Why Current Policies May Make Matters Worse, 30 HeALTH AFF. 1852, 1854-55 (2011) (footnotes omitted); see also Evans et al., supra note 89, at 9 (discussing that " $\mathrm{t}]$ he health challenges faced by individuals and households are influenced by the neighborhood. Regardless of one's education, income, or motivation to make healthy choices, risks may be introduced by increased crime, air pollution, the absence of places to exercise or nutritious food, poor schools, a scarcity of good jobs, and stress related to these community challenges. Historical patterns contribute to long-term trends of placing vulnerable populations in stressed areas. This in turn reinforces cycles of hardship that entrench patterns of socioeconomic disadvantage.") (footnotes omitted).

922016 County Health Rankings: Key Findings Report, U. Wis. Population Health Inst. \& ROBERT WOOD JOHNSON FOUND., http://www.countyhealthrankings.org [http://perma.cc/3N72WTT5] (last visited May 7, 2016).

${ }^{93}$ Chetty et al., supra note 74 , at 1754, 1756, 1758,763.

${ }^{94}$ Irene Dankwa-Mullan \& Eliseo J. Pérez-Stable, Addressing Health Disparities Is a PlaceBased Issue, 106 Am. J. PuB. HeAlth 637, 637 (2016) (stating that an "equitable approach to 
for many reasons, including differences in access to healthy food, ${ }^{95}$ air quality and pollution, ${ }^{96}$ and proximity to noxious hazards. ${ }^{97}$ Recognizing the key roles that social and environmental conditions play in health, the federal government's Healthy People 2020 initiative now includes, as one of its four overarching goals, to "create social and physical environments that promote good health for all. $" 98$

\section{Lack of Progress on Eliminating Health Disparities}

Despite extensive progress on implementing many of the IOM recommendations as discussed above, ${ }^{99}$ the needle has hardly moved on actually reducing health disparities in this country. Reflecting on the lack of progress in reducing health disparities since the Heckler and IOM reports were released, James Marks, Executive Vice President for RWJF, recently observed that, despite

building healthy communities requires place-based approaches that involve the community and stakeholders. Place is characterized by structural resources such as schools, hospitals, recreational facilities, retail outlets, and housing. Healthier places have health-promoting environments such as parks, safe walking spaces, maintained homes, full-service food stores, and environmental protection.").

${ }^{95}$ CDC HeAlTh DisPaRities 2013 RePORT, supra note 71, at 22 (finding that "[i]n 2011, 30.3\% of census tracts did not have at least one healthier food retailer within the tract or within $1 / 2$ mile of tract boundaries ... Persons in rural census tracts were approximately four times as likely to lack access to a healthy food retailer than persons in urban tracts"); see also Lauren Fiechtner et al., Effects of Proximity to Supermarkets on a Randomized Trial Studying Interventions for Obesity, 106 AM. J. PUB. HeAlth 557, 557-62 (2016) (concluding that living closer to a supermarket is associated with greater improvements in fruit and vegetable intake and weight status); Renee E. Walker et al., Disparities and Access to Healthy Food in the United States: A Review of Food Deserts Literature, 16 HEALTH \& PLACE 876, 876-84 (2010) (systematic study of food access and food deserts research in United States).

${ }^{96}$ CDC HEAlTh DisParities 2013 RePort, supra note 71, at 46 (stating that "[i]n the United States, it is widely accepted that economically disadvantaged and minority populations share a disproportionate burden of air pollution exposure and risk."); see also Fabio Caiazzo et al., Air Pollution and Early Deaths in the United States, Part I: Quantifying the Impact of Major Sectors in 2005, 79 ATMOSPHERIC ENV'T 198, 198-208 (2013) (finding that air pollution caused by concentrations of fine particulate matter and ozone is associated with premature mortality and morbidity, with road transportation and power generation having the largest adverse impacts on health).

97 Juliana Maantay, Zoning, Equity, and Public Health, 91 AM. J. PuB. HeAlth 1033, 103839 (2001) (stating that "[z]oning tends to concentrate noxious uses in poor and minority industrial neighborhoods as more affluent industrial neighborhoods with lower minority populations are rezoned to other uses").

${ }^{98}$ HealthyPeople.gov Off. Disease Prevention \& Health Promotion, Social Determinants of Health, HEALTHYPEOPLE.GOV, https://www.healthypeople.gov [http://perma.cc/DEB5-UECQ] (last visited May 7, 2016).

99 See supra notes 38-72 and accompanying text (discussing progress on implementing IOM UNEQUAL TREATMENT report's recommendations). 
being prominent reports "in their time," they "seem not to have generated substantial, sustained, and broad commitment to the elimination of the differences found" in those reports. ${ }^{100}$

The HHS Disparities Action Plan, issued in 2011, observed that the "leading health indicators have demonstrated little improvement in disparities over the past decade . . Significant racial and ethnic health disparities continue to permeate the major dimensions of health care, the health care workforce, population health, and data collection and research." ${ }^{101}$ With respect to data collection and research, it observed that the "lack of standards related to data collection remains a challenge for adequately collecting, reporting, and tracking data on health disparities." 102 A recent progress report on the HHS Disparities Action Plan, issued at the end of 2015, reiterated that blunt acknowledgement: "Many leading health indicators, such as those from the Healthy People 2010 Final Review and the Agency for Healthcare Research and Quality (AHRQ) National Healthcare Disparities Report, have shown little reduction in racial and ethnic health disparities over the past decade." "103 The NPA Stakeholder Strategy observed that there remains a low level of awareness of health disparities among the American public and among health care providers, and there is still little evidence for proven community strategies and programs that work to reduce health disparities. $^{104}$

100 James S. Marks, Video, Remarks to the Committee on Community Based Solutions to Promote Health Equity in the United States, The NAT'L ACAD. OF SCI, ENGINEERING AND MED., at 3:24-3:33 (Jan. 6, 2016), http://www.nationalacademies.org/ [https://perma.cc/LA5X-9JLQ].

${ }^{101}$ HHS Disparities Action Plan, supra note 57, at 2; see also, INST. OF MED., How FAR HAVE We Come in Reducing Health Disparities? Progress Since 2010, Workshop Summary 1322, (Karen M. Anderson, Rapporteur, Washington, D.C.: The National Academies Press, 2012) (remarks of David Williams, discussing the persistence of health disparities by race and ethnicity over time); Edward J. Sondik et al., Progress Toward the Healthy People 2010 Goals and Objectives, 31 AnN. REV. OF PUB. HeAlth 271, 280-81 (2010) (concluding that "[o]verall, in the area of the disparity reduction, there is not much good news. According to our analysis, not much progress has been made, to date, in moving toward the reduction and ultimate elimination of disparities in health ... We expect that we will fall short of the majority of the Healthy People 2010 targets associated with [leading health indicator] measures").

${ }^{102}$ HHS Disparities Action Plan, supra note 57, at 5.

${ }^{103}$ HHS Disparities Action Plan Progress Report, supra note 57, at 6 (citing Healthy People 2010: final review, U.S. DEP'T OF HEALTH AND HuM. SERV., http://www.cdc.gov [https://perma.cc/JX3S-KGUD]).

${ }^{104}$ NPA Stakeholder Strategy, supra note 56, at 109 (commenting that "[v]arious reports over time ... have shown that Americans and health professionals are not sufficiently informed about health and healthcare disparities."); Id. at 132 (finding that "[w]hile research to document these disparities has continued and improved, the research to identify their social and environmental determinants still lags behind-as have the development, dissemination, and translation of scientifically proven models for changing these conditions ... Thousands of programs have been initiated, yet most are not evaluated effectively to determine whether they worked, for whom, and in what way."); see also Anderson, supra note 101, at 27 (remarks of David Williams, observing that "most Americans from all racial and ethnic groups are still unaware of the existence of health disparities. Although these issues have been discussed for years, even most African Americans are unaware of the disparities in rates of infant mortality and life expectancy between African 
In 2013, the CDC's report on health disparities comprehensively surveyed the persistence of health disparities across a broad range of social determinants of health, environmental hazards, access to health care, behavioral risk factors, and morbidity and mortality in health outcomes, and it concluded that "disparities were found between race and ethnic groups across all of the health topics explored." "105 The only indicators of progress in reducing health disparities that was cited in this report were the elimination of disparities in childhood vaccination rates and access to health insurance coverage due to the ACA. ${ }^{106}$

In its latest National Healthcare Quality and Disparities Report, AHRQ acknowledged progress reducing disparities in some areas (e.g., childhood vaccination rates, rates of adverse events), and also made some key findings that through 2012:

Few disparities were eliminated. People in poor households generally experienced less access and poorer quality. Parallel gains in access and quality across groups led to persistence of most disparities ... Many challenges in improving quality and reducing disparities remain... [D]isparities in quality and outcomes by income and race and ethnicity are large and persistent, and were not, through 2012, improving substantially. Some disparities related to hospice care and chronic disease management grew larger. ${ }^{107}$

Progress has been similarly slow to nonexistent on achieving eight objectives in Healthy People 2020 related to the social determinants of health. Two objectives showed slight improvement since 2010: the number of kids with a full-time employed parent has increased, and the number of children living in poverty has decreased slightly. ${ }^{108}$ Progress on the other objectives either has shown no improvement or has worsened since data over the years began to be compared: proportion of high school completers enrolled in college; proportion of all people living in poverty; proportion of all households and poor households (earning less than $200 \%$ of poverty level) that spend more than $30 \%$ of income on housing; and proportion of all households and renter households that spend more than $50 \%$ of income on housing. ${ }^{109}$

Americans and whites."); Id. at 73-74 (remarks of Paula Braveman, explaining that "a massive expansion in intervention research is needed ... '[G]oing to scale' is the next step because research has already demonstrated success on a small scale . . . [M]ore translational research that will translate the existing knowledge base into action is strongly needed . . . [T] he biggest barrier to reducing health disparities is not a lack of knowledge; rather it is a lack of political will.").

${ }^{105}$ CDC Health Disparities 2013 Report, supra note 71, at 184; see also id. at 3. (finding that "[d] uring the past decade, documented disparities have persisted for approximately $80 \%$ of the Healthy People 2010 objectives and have increased for an additional 13\% of the objectives.")

${ }^{106} \mathrm{Id}$. at 1 . More recently, these two indicators of progress in reducing health disparities were the only ones cited by HHS Secretary Sylvia Mathews Burwell, in HHS Blog, Minority Health Month. Sylvia Mathews Burwell, Minor Health Month: Making Progress on Health Disparities, HHS.GOV (Apr. 13, 2015), http://www.hhs.gov [https://perma.cc/T258-YPYL].

107 AHRQ, 2014 Disparities Report, supra note 70, at 2.

${ }^{108}$ HeALTHYPEOPLE.GOV., supra note 98.

${ }^{109} \mathrm{Id}$. 


\section{Institutional and Structural Barriers to Reducing Health Disparities}

While there may be a sense in some societal quarters that we are in a "post-racial" America, structural inequalities and racial discrimination persist at significant levels in the United States and contribute to health disparities. ${ }^{110}$ Title VI does not address many of the structures and practices within the health care that have resulted in racially separate and unequal systems. ${ }^{111}$ Although there has been some evidence of positive trends in mortality and access to health care generally in recent years, albeit not reducing the overall gaps along racial and socioeconomic lines, there has been concern expressed that "the country is only 'nibbling at the margins' rather than dealing with big policy questions." 112 A leading health scholar has pointed to the impact of institutionalized racism, independent of socioeconomic differences, on health:

The effects of institutionalized racism may mean that a child born to an African American family is far more likely to grow up in a neighborhood with fewer opportunities and more adverse effects on health. Residential segregation systematically tracks certain racial and ethnic groups into worse living and working conditions. The effects of crime, toxic hazards, a lack of safe areas to play or exercise, a lack of access to healthy foods, and an environment filled with despair are all part of an important potential pathway through which disparities are played out. ${ }^{113}$

The current president of the American Public Health Association, Camara Phyllis Jones, has also written about institutional racism and the historical contributions of governmental action and inaction to address it:

[I]nstitutionalized racism is defined as differential access to the goods, services, and opportunities by race. Institutionalized racism is normative, sometimes legalized, and often manifests as inherited disadvantage. It is structural, having been codified in our institutions of custom, practice, and law, so there need not be an identifiable perpetrator . . . Institutionalized racism manifests itself both in material conditions and in access to power. With regard to material

110 ANDERSON, supra note 101, at 8-13.

${ }^{111}$ See generally Ruqaiijah Yearby, Sick and Tired of Being Sick and Tired: Putting an End to Separate and Unequal Health Care in the United States 50 Years After the Civil Rights Act of 1964, 25 HEALTH MATRIX 1 (2015); WATSON, supra note 31.

112 AnDERSON, supra note 101, at 28.

${ }^{113}$ Id. at 71 (remarks of Paula Braveman); See also Paula Braveman, Health Inequalities by Class and Race in the US: What Can We Learn from the Patterns?, 74 Soc. SCI. \& MED. 665, 666 (2012), http://scholar.harvard.edu [https://perma.cc/7LQT-NF5E ] (observing that the "disproportionate representation of Blacks, Latinos, and American Indians among the socieconomically disadvantaged reflects what has been called 'structural racism'-a selfperpetuating form of bias built into structures and institutions, even when conscious intent to discriminate is no longer present."). 
conditions, examples include differential access to quality education, sound housing, gainful employment, appropriate medical facilities, and a clean environment. ${ }^{114}$

Calls are increasing for broad structural reforms that acknowledge the role of racial and ethnic bias in perpetuating social injustice and health inequities across social institutions, within and beyond the healthcare system. ${ }^{115}$

Residential racial segregation has been called a primary institutional mechanism of racism and a fundamental cause of racial disparities in health. ${ }^{116} \mathrm{~A}$ tragic example of this kind of institutional racial injustice is the lead poisoning of Flint, Michigan residents through the city's public water supplies, which made national headlines recently. For over a year and a half, Flint residents had complained about tinted and smelly water coming through their water taps, which turned out to have been caused by water flowing from the nearby Flint River, which had been redirected to Flint, corroding the city's pipes, and leaching lead into the water supply. ${ }^{117}$ Government officials ignored the complaints and insisted the water was fine. ${ }^{118}$ Meanwhile, the exposure to the lead in the water was poisoning the residents, and the harmful effects first began to appear in children, who are particularly vulnerable to long-lasting harm from lead poisoning. ${ }^{119}$

After much delay, an Advisory Task Force was ultimately commissioned by the Michigan Governor to investigate the water crisis and make recommendations. In its Final Report, the Task Force bluntly concluded:

The facts of the Flint water crisis lead to the inescapable conclusion that this is a case of environmental injustice. Flint residents, who are majority Black or African American and among the most impoverished of any metropolitan area in the United States, did not enjoy the same degree of protection from environmental and health

114 Camara Phyllis Jones, Levels of Racism: A Theoretic Framework and a Gardener's Tale, 90 Am. J. of Pub. HeAlth no. 8, 1212 (August 2000).

115 Dayna Bowen Matthew, Toward a Structural Theory of Implicit Racial and Ethnic Bias in Health Care, 25 HEALTH MATRIX no. 61, 84 (2015) (“"S]tate-perpetuated social injustice may lead to many related inequities as well, such as unequal housing, inferior education, and lack of safe environments, healthy food, and fair employment. All of these inequalities are structural, not individual, and fixing them will likely require structural changes to the larger context in which health care delivery occurs.").

116 David R. Williams \& Michelle Sternthal, Understanding Racial-ethnic Disparities in Health: Sociological Contributions, J. Of Health And Soc. Behav. 15, S20 (Supp. 2010); see also David Barton Smith, Separate and Unequal: Racial Segregation and Disparities Across U.S. Nursing Homes, 26 HEALTH AFF. no. 5, 1448-58 (2007) (discussing residential segregation in U.S. cities that results in blacks being disproportionately placed in poorer-performing nursing homes).

117 Josh Sanburn, The Toxic Trap: How a Disastrous Chain of Events Corroded Flint's Water System, TIME, Feb. 2016, at 32-39.

$118 \mathrm{Id}$.

119 Mona Hanna-Attisha et al., Elevated Blood Lead Levels in Children Associated with the Flint Drinking Water Crisis: A Spatial Analysis of Risk and Public Health Response, 106 AM. J. of Pub. Health no. 2, 283-290 (2016). 
hazards as that provided to other communities ... [I]rrespective of the intent of the parties involved, the simple reality is that the Flint water crisis is a case of environmental injustice. ${ }^{120}$

Institutional racism that results in such environmental injustice is strongly intertwined with class-based differences in the socioeconomic determinants of health. ${ }^{121}$ Indeed, while both class and race are reflected in institutional and structural barriers to improving health equity, there is evidence that class may be an even stronger determinant of health and health disparities than race. ${ }^{122}$ Class, or socioeconomic status ("SES"), can be measured by education, income and wealth, and employment, which as we have seen can impact health and whose differences are associated with health disparities. ${ }^{123}$ Even while consensus has grown that racial disparities were unjust, however, there has been resistance to acknowledging that class differences in this country were unjust which has led some commentators to conclude that:

[O]pposing racial inequalities in health has the appeal of ridding all of us of a historical anomaly, a vestige of an unjust past . . . By contrast, class inequalities are intrinsically divisive: It is not us against them, but some of us against some of us. Political struggle is unavoidable ... so there are formidable obstacles to making class inequalities in health the focus of policy reform. ${ }^{124}$

\section{E. Health (and Health Equity) in All Policies}

In light of the impact that diverse social, economic, and environmental factors have on health and health disparities, these class-based and race-based determinants of health must be addressed at the level of societal infrastructure if progress is to be made in reducing health disparities. As discussed above, the structural barriers to health equity go far beyond those related to health care

120 Flint WAter Advisory TASk Force, Final Report 54 (March 2016), https://www.michigan.gov (last visited May 7, 2016) [https://perma.cc/YW66-QXDU].

${ }^{121}$ Williams \& Sternthal, supra note 116, at S19 (concluding that "attention needs to be given to both race-based and class-based factors that undergird racial health disparities.").

${ }^{122}$ Stephen L. Isaacs \& Steven A. Schroeder, Class-The Ignored Determinant of the Nation's Health, 351 NEw ENG. J. OF MED. 11, 1139 (2004); see also Jack M. Guralnik et al., Educational Status and Active Life Expectancy Among Older Blacks and Whites, 329 NEW EnG. J. OF MED. 2, 110-116 at 110 (1993), (finding that "[a]mong older blacks and whites, the level of education, a measure of socioeconomic status, has a greater effect than race on total life expectancy and active life expectancy.").

${ }^{123}$ See supra text accompanying notes 73-98 (discussing the socioeconomic determinants of health).

${ }^{124}$ Ichiro Kawachi, Norman Daniels, \& Dean E. Robinson, Health Disparities By Race and Class: Why Both Matter, 24 Health AfF. 2, 349-50 (March/April 2005); see also Isaacs \& Schroeder, supra note 122, at 1141 (concluding that "a nation that is serious about improving the health of its people will have to go beyond expanding medical care, changing unhealthy behavior, and improving the environment and give more attention to social policies that address the classas well as the racial and ethnic-differences that underlie illness and premature death."). 
access and delivery. The barriers include laws and policies related to education, housing, employment, food and agriculture, income and taxes, transportation, urban planning and zoning, recreation, crime and public safety, and other non-health sectors that impact health. This understanding has led to numerous calls for a "health in all policies" ("HiAP") approach to reducing health disparities, challenging policymakers go beyond the health care and public health sectors and to consider the health ramifications of policies in these other diverse, non-health sectors. ${ }^{125}$

A HiAP framework can include performing a health impact assessment ("HIA") during the evaluation process of a proposed policy, law, or project to determine its potential effects on the health of a population. ${ }^{126}$ HIAs have been undertaken to look at the health impacts of a wide array of policies, such as a proposed living wage ordinance, state funding for the federal Low Income Energy Assistance Program, a planned express bus route, and a proposed wind energy project. ${ }^{127}$

To be effective, undertaking a HiAP approach to policy-making requires the collaboration of diverse stakeholders, including government agencies, businesses, non-profit stakeholders, and community partners. ${ }^{128}$ A HiAP framework encourages government agencies and private sector stakeholders to collaborate and consider intersectoral strategies to understand how non-health sector actions could affect the public's health, for example:

Non-health policies range from those that affect socioeconomic status and other indirect factors to those that shape individual behaviors more directly. Examples of the former include housing, employment, and educational policies. Policies in these areas may offer incentives for low-cost safe and decent housing, provide a

${ }^{125}$ Health Policy Brief, supra note 78, at 6-7; see also Linda Rudolph et al., Health in All Policies: A Guide for State and Local Governments, Pub. Health Inst. and Am. Pub. Health Ass'N, 1 (2013), https://www.apha.org [https://perma.cc/EV5J-4D9E] (last visited May 7, 2016) ("Responsibility for the social determinants of health falls to many non-traditional health partners, such as housing, transportation, education, air quality, parks, criminal justice, energy, and employment agencies."); Woolf \& Purnell, supra note 75, at 1708 (A "culture of collaboration across sectors provides a venue for medicine and public health to join forces with business leaders, school systems, the park authority, investors, retailers, the media, and community groups ... [T] he answer cannot come from medicine or public health alone but from the health professions working with partners who share an interest in prosperity and good health. Finding common causes, bridging silos, and leveraging talents hold promise of much deeper influence and benefit that yesterday's fragmented efforts could achieve.").

${ }^{126}$ Rudolph et al., supra note 125, at 84; see also Health Impact Project, THE PEW CHARITABLE TRUSTS, http://www.pewtrusts.org [https://perma.cc/U9WZ-BUFF] (last visited May 7, 2016) (stating that the project is a "national initiative designed to promote the use of health impact assessments ("HIA"s) as a decision-making tool for policymakers.").

${ }^{127}$ Rudolph et al., supra note 125 , at 85.

${ }^{128}$ Id. at 1; see also World Health Organization, Health in All Policies: Training MANUAL, at xi, http://apps.who.int/iris/bitstream [https://perma.cc/BZU5-JZHN] (last visited May 1, 2016) (stating that the HiAP "approach . . promotes collaboration between government sectors and non-government stakeholders to maximize the health benefits of government policies and reduce health inequalities ...") [hereinafter WHO HiAP Training Manual]. 
living wage that allows greater financial stability for families, and provide funding for community colleges, which increase educational attainment and income - all of which are linked to better health. Examples of the latter include government agricultural subsidies that influence food choice, as demonstrated by preference for foods of low or no nutritional value, and educational policy that emphasizes certain aspects of the curriculum to the complete detriment of physical activity. ${ }^{129}$

Taking a HiAP approach to the obesity epidemic, for example, policy analysts might look to needed policy:

changes in schools, workplaces, advertising, the food industry, restaurants, parks, public transportation, tax policy, and clinical care. A coordinated approach to this problem therefore requires policymakers in each of these sectors to consider their respective role in addressing obesity and how best to harmonize their efforts with other sectors. ${ }^{130}$

Complementary legal interventions across these sectors that could be used to enhance policies to address the obesity epidemic include requiring disclosure of calorie contents, imposing taxes on unhealthy foods, outright bans on some food products (e.g., sugar-sweetened beverages), using zoning laws to limit the opening of fast-food restaurants in neighborhoods, restricting the marketing of unhealthy foods to children, adopting "complete streets" laws to ensure safety and convenience and encourage physical activity, subsidizing the provision of healthy foods, and eliminating subsidies for unhealthy ingredients. ${ }^{131}$

${ }^{129}$ Inst. of Med., For the Public’s Health: Revitalizing Law and Policy to Meet New Challenges 3 (June 2011), http://www.nationalacademies.org/hmd [https://perma.cc/Y53ZZFP9] (last visited May 7, 2016); see also Woolf \& Braveman, supra note 91, at 1856 (suggesting that under a HiAP approach, "a city council might replace an abandoned warehouse with a public park, or offer tax incentives for supermarkets to locate in a 'food desert' neighborhood").

${ }^{130}$ Inst. of Med. Committee on Public Health Strategies to Improve Health, For the Public's Health: Revitalizing Law and Policy to Meet New Challenges, 80 (2011), https://www.nap.edu [https://perma.cc/9DQW-2GDG]. [hereinafter IOM Revitalizing Law and Policy]; see also Rudolph et al., supra note 125, at 14 (observing that "[t]ransportation, planning, agriculture, labor, economic development, education, entertainment, and other partners will all need to be involved in order to advance a comprehensive approach to obesity and chronic disease prevention.").

${ }^{131}$ See generally Deborah L. Rhode, Obesity and Public Policy: A Roadmap for Reform, 22 VA. J. SOC. POL'Y \& L. 491 (2015); see also IOM Revitalizing Law and Policy, supra note 130, at 59 (providing legal models of intervention applied to food and nutrition, including subsidies for healthy school lunches, disclosure of calories on restaurant menus, laws on fast-food restaurant density, and ending subsidies for agricultural products that contribute to unhealthy eating); Fazal Khan, Combating Obesity through the Built Environment: Is There a Clear Path to Success?, 39 J.L. MED. \& ETHICS 387, 387-93 (2011) (discussing promise of Community Transformation Grant 
Utilizing a HiAP framework to policy-making has been widely endorsed, including by the World Health Organization, ${ }^{132}$ the American Public Health Association ("APHA"), ${ }^{133}$ the CDC, ${ }^{134}$ the Institute of Medicine, ${ }^{135}$ and the National Association of County and City Health Officials. ${ }^{136}$ Some advocates encourage going even further to implement an explicit focus not just on the health impacts of proposed policies, but also on their impacts on health equity, to both improve health and reduce health disparities. ${ }^{137}$ The APHA has collected case studies of successful examples when an explicit health equity lens was taken in policy-making. ${ }^{138}$

Although implementing policies within a HiAP framework does not necessarily entail changes in law, legislation or agency regulations can often be important tools for institutionalizing social change, and for ensuring that agencies pursue public health-promoting policies. ${ }^{139}$ Laws that impact health cut across nearly all sectors of society-from those specifically addressing such diverse fields as firearms, motor vehicles, environmental protections, agricultural subsidies, food labeling, and indoor smoking bans, to more generally exerting influence on such diverse fields as economic policy design, employment opportunities, the tax code, educational reforms, financial aid programs, and other social structures that can impact health. ${ }^{140}$ When government agencies and other stakeholders take a HiAP approach to policy-making, the role that law and lawyers can play

program for analyzing relationship between obesity and the built environment and for adopting HiAP approach to the problem).

132 WHO HiAP Training Manual, supra note 128.

${ }^{133}$ Rudolph et al., supra note 125.

${ }^{134}$ CDC Office of the Associate Director for Policy, Health in All Policies, http://www.cdc.gov [https://perma.cc/CK2C-H25K].

${ }^{135}$ IOM Revitalizing Law and Policy, supra note 130, at 84 (recommending that states and federal government employ a HiAP approach to consider health effects - both positive and negative - of major legislation, regulations, and other policies that could potentially have a major impact on the public's health).

136 NACCHO, Health Impact Assessment, http://www.naccho.org [https://perma.cc/44JC8TTA] (The National Association of County and City Health Officials ("NACCHO") assists local health departments to implement a HiAP approach by using a health impact assessment in "community design, transportation, parks and recreation, housing, land use planning decisions, etc.").

137 Mary Hall, et al., Policy Approaches to Advancing Health Equity, 22 J. PuB. HeAlth Mgmt. Practice 1 S50, S59 (2015); Donald Acheson, supra note 78, at 16 (recommending "that as part of health impact assessment, all policies likely to have a direct or indirect effect on health should be evaluated in terms of their impact on health inequalities, and should be formulated in such a say that by favoring the less well off they will, wherever possible, reduce such inequalities."); see also HHS Disparities Action Plan, supra note 57, at 28 (HHS is evaluating pilot tests of health disparity impact assessments of selected proposed national policies and programs).

138 American Public Health Association, Better Health Through Equity: Case Studies IN Reframing Public HeAlth Work (March 2004), https://www.apha.org [https://perma.cc/83TL-UTV7] (describing five case studies that implemented an explicit health equity framework in undertaking public health initiatives).

${ }^{139}$ IOM Revitalizing Law and Policy, supra note 130, at 86.

${ }^{140}$ Id. at 87. 
in addressing the socioeconomic determinants of health will be less dependent on an antidiscrimination framework than on how laws can alter these determinants and the root causes of health disparities as well as the institutional and structural barriers to achieving health equity.

\section{THE FUTURE}

\section{A. Promising Directions for Legal Interventions to Promote Health and Health Equity}

There is growing recognition that law has an affirmative role to play in addressing the social determinants of health and reducing health disparities. ${ }^{141}$ For starters, the ACA represents a significant role for law in achieving equity in health care access and delivery. ${ }^{142}$ A number of innovative legal interventions to improve the public's health and reduce health disparities have also been enacted or proposed to promote structural changes outside of health care settings. For example, to address the disproportionate impact of air pollution due to road transportation, particularly among children in vulnerable communities, California enacted a public health law to restrict the building of new schools near major highways and busy traffic corridors. ${ }^{143}$ Similarly, placing a public health initiative in school settings to combat obesity, which disproportionately affects minority children, California was the first state to ban soft drinks in schools, and other states have followed its model, "providing an example of how a promising practice at the local level can be scaled up." "144

As has been observed, "all disparities are local," and while national research is useful for gathering an evidence base to create an action plan, what is needed to effect real change are more localized and focused action plans. ${ }^{145}$ Consequently, there is a strong trend to address health

141 Wendy E. Parmet, et al., Poverty, Health and Law: Readings and Cases for Medical-Legal PARTNERShIP 1-36 (Elizabeth Tobin Tyler et al. eds., 2011) (discussing that "[1] aw is one of the most important social determinants of health. It helps establish the framework in which individuals and populations live, face disease and injury, and eventually die. By doing so, law influences a myriad of other social determinants, including education, income, housing, racial and ethnic disparities, nutrition and access to health care. In short, law is one factor that helps determine other social determinants."); see also CDC, supra note 33 (identifying recent CDC and RWJF initiatives to promote the role of law and lawyers in promoting the public's health); see Paula Braveman, Social Conditions, Health Equity, and Human Rights, 12 HEALTH AND HuMAN Rights, J. 2， 31， 43 (2010) http://www.hhrjournal.org [https://perma.cc/PN5D-RWET] (discussing general human rights laws, principles and health equity concepts, and observing "the legal nature of human rights concepts and instruments is a precious and unique resource. The basis of human rights in international agreements between authorized state representatives, whether legally binding or not, and whether universally enforced or not, is perhaps the most powerful contribution that human rights can make to health equity efforts.").

${ }^{142}$ See supra notes 41-43.

143 CDC Health Disparities 2013 Report, supra note 71, at 49; see CAL. EDU. CODE § 7213.c2.C) (stating that "[f]uture and ongoing efforts to address disparities in residential proximity to major highways and traffic-related air pollution exposures will require an interdisciplinary collaboration between transportation, urban planning, and public health specialists.").

${ }^{144}$ Anderson, supra note 101, at 67.

${ }^{145} \mathrm{Id}$. at 75. 
disparities at the local level by investing in place-based initiatives in local communities. A good example of this is the California Endowment's Building Healthy Communities Initiative, which focuses on improving the health of underserved communities in the state through place-based strategies and empowering local communities to determine for themselves needed changes in the policies and systems that affect them. ${ }^{146}$ The CDC's Racial and Ethnic Approaches to Community Health ("REACH") also focuses on funding local communities' efforts to plan and carry out local, culturally appropriate programs to address a wide range of health issues in minority communities. ${ }^{147}$ Examples of community strategies supported by REACH include: anti-smoking initiatives, encouraging healthy eating, improving the affordability of healthy foods and beverages, increasing physical activity opportunities, and increasing the number of multidisciplinary, culturally-competent health care teams to help patients manage chronic disease. ${ }^{148}$

Effective local health strategies emphasize strong community participation and engagement for success. ${ }^{149}$ While legal mandates for certain individual behaviors are a common public health law tool, they can have unintended negative consequences, and legal interventions that rely on "nudges" rather than legal coercion to encourage desired behaviors should also be promoted. ${ }^{150}$

Not all community-based initiatives to promote the public's health necessarily involve law and lawyers, although a number of promising ones do. ${ }^{151}$ An IOM committee recently concluded that "an array of legal and policy tools is available to help local, state, and federal governments promote

146 Investing In Place, THE CAL. ENDOWMENT, http://www.calendow.org/places/ [https://perma.cc/KPT6-YCYW] (last visited May 7, 2016) (“[B]ecause the differences between neighborhoods is linked to differences in health outcomes, The California Endowment's Building Healthy Communities initiative includes a deep investment in place."); see generally Anderson, supra note 101, at 64-68 (discussing the Building Healthy Communities Initiative).

147 Racial and Ethnic Approaches to Community Health, CTR. FOR DisEASE CONTROL AND PREVENTION, http://www.cdc.gov [https://perma.cc/36BN-G7RZ] (last visited May 7, 2016).

148 REACH 2014, CTR. FOR DiSEASE CONTROL AND PREVENTION, http://www.cdc.gov [https://perma.cc/G27G-KEYE] (last visited May 7, 2016).

${ }^{149}$ David Satcher, Our Commitment to Eliminate Racial and Ethnic Health Disparities, 1 YALE J. HEALTH POL'Y, L., AND ETHICS 1, 3 (2001) (“'[C]ommunities experience the greatest success in addressing health and quality-of-life issues have drawn upon public health, health care, business, local governments, schools, civic organizations, voluntary health organizations, faith-based organizations, park and recreation departments, and other interested groups and private citizens. Communities . . . are more likely to be successful if they work collaboratively within their communities ...").

${ }^{150}$ Wendy E. Parmet, The Individual Mandate: Implications for Public Health Law, 39 J.L. MED. \& ETHICS 401, 401-13 (2011) (concluding that "[B]y focusing on the responsibility of individuals and holding them responsible for socially constructed choices, mandates may also undermine support for public health laws ...").

${ }^{151}$ See James G. Hodge, Jr., et al., Legal Innovations to Advance a Culture of Health, 43 J.L. MED \& ETHICS 904, 904-12 (2015) (discussing modern examples of innovations in law and policy that have the potential to promote systemic public health improvements through societal collaborations). 
and protect the public's health," and urges legislatures and regulatory agencies to deploy them. ${ }^{152}$ The committee included the following in this array of legal tools:

- Imposing taxes or providing financial incentives - e.g., subsidies for healthy school lunches; taxes on unhealthy foods

- Altering the informational environment - e.g., laws related to product labeling

- Altering the built/physical environment - e.g., zoning laws

- Direct regulation - e.g., safety laws, food fortification laws

- Indirect regulation - e.g., tort liability for harmful products (e.g., tobacco) or false advertising liability for company's misleading claims about product

- Deregulation - e.g., end agricultural subsidies that contribute to unhealthy eating (e.g., corn-based sweeteners and fillers). ${ }^{153}$

Medical-legal partnerships ("MLPs") offer a promising way for lawyers to collaborate with health professionals to address the social, economic, and environmental determinants of health. ${ }^{154}$ Typically, an MLP is a community collaboration between an institutional health care provider (hospital or outpatient care facility) and attorneys, either with a legal aid society or law school clinical program, to provide free legal services to low-income patients. While health care professionals focus on a patient's medical needs, the attorneys address legal concerns that typically implicate socioeconomic and environmental factors adversely affecting the patient's health. These factors could include housing problems (e.g., substandard housing conditions like mold and infestations that exacerbate asthma), family stability (e.g., food insecurity, domestic violence, or guardianship to consent for health care), economic stability (e.g., employment rights), and educational needs (e.g., individualized education programs for disabled or chronically ill children).

MLPs thus offer a way for communities to collaborate to provide a comprehensive, holistic set of medical and legal services to improve the health of low-income patients. Because the patient population is often comprised of members of minority and disadvantaged communities, they also offer a way to reduce health disparities. As of this writing, MLPs have been established in 294 health care institutions in forty-one states across the country. ${ }^{155}$

152 IOM Revitalizing Law and Policy, supra note 130, at 68.

${ }^{153}$ Id. at 58-68; see generally Jonathan Wolff, Paying People to Act in Their Own Interests: Incentives versus Rationalization in Public Health, 8 PUB. HeAlth ETHICS, 1, (2015) at 27-30 (for a series of articles on the role of direct financial incentives to promote healthy individual behaviors (e.g., paying children to read, paying pregnant women to give up smoking)); see also Mathias Kifmann, Comment on Jonathan Wolff, Paying People to Act in Their Own Interests: Incentives versus Rationalization in Public Health, 8 Pub. HeAlth Ethics, 1, (2015) at 27-30; see also Moti Gorin, "I Did It for the Money": Incentives, Rationalizations and Health, 8 PUB. HeALth ETHICS, $1,(2015)$ at 27-30.

154 See generally Symposium, Medical-Legal Partnerships: Collaborating to Transform Healthcare for Vulnerable Patients, 35 J. LEGAL MED., 1, 1-177 (2014) (for a comprehensive set of recent writings about MLPs).

155 NAT'L CTR. FOR MED.-LEGAL P'SHIP, http://medical-legalpartnership.org/ [https://perma.cc/C84W-VUQV] (last visited May 7, 2016). 
Impact-advocacy litigation is another example of a legal intervention that can promote health in minority and disadvantaged communities. ${ }^{156}$ For example, a court recently declined to dismiss a class-action lawsuit filed on behalf of children living in Compton, California, who have suffered trauma through exposures to violence, loss, and other adverse childhood experiences. The lawsuit addresses the public health concern that childhood trauma can adversely impact learning. ${ }^{157}$ Compton is among the most socioeconomically distressed cities in Southern California, with a poverty rate that is twice the national average and murder rate that is five times the national average. ${ }^{158}$ Under a novel legal theory, the litigation alleges that "complex trauma" should be recognized as a protected disability under the Americans with Disabilities Act and Section 504 of the Federal Rehabilitation Act, ${ }^{159}$ and that the Compton Unified School District has denied the children meaningful access to public education on account of their disabilities and should be required to provide reasonable accommodations, such as mental health services for the children and training for teachers and administrators to understand and address the effects of complex trauma. ${ }^{160}$ Potentially, "the lawsuit could set precedent regarding the role schools can play in a child's mental health, especially in lower-income and crime-heavy neighborhoods."161

Promising partnerships between health care organizations and their communities to address the social and environmental determinants of health are also beginning to take hold, due in part to a new requirement under the ACA for nonprofit hospitals to qualify for tax exemption. These hospitals must now undertake "community health needs assessments" every three years and analyze and respond to the health needs of their communities. ${ }^{162}$ This new law offers opportunities, as well as motivation, for hospitals to think and work outside their institutional walls and address the social determinants of health in their communities. ${ }^{163}$

${ }^{156}$ Parmet et al., supra note 141, at 29 ("[I]mpact lawsuits differ from traditional, individually centered advocacy in that they self-consciously seek to utilize the judicial system to make broadlybased changes.").

157 Did You Know?, TRAUMA AND LEARNING, http://www.traumaandlearning.org [https://perma.cc/5M3W-3UVY] (last visited May 7, 2016).

158 Why Compton?, TRAUMA AND LEARNING, http://www.traumaandlearning.org [https://perma.cc/3FPW-83GA] (last visited May 7, 2016).

159 P.P., et al. v. Compton Unified Sch. Dist., 135 F. Supp. 3d 1098 (C.D. Cal 2015) (order denying defendants' motion to dismiss plaintiffs' class action complaint).

${ }^{160} \mathrm{Id}$.

161 Angela Almeida, Holding Schools Responsible for Addressing Childhood Trauma, THE ATLANTIC (May 19, 2015), http://www.theatlantic.com [https://perma.cc/9V9U-P5EP] (last visited May 7, 2016).

162 Mary Crossley et Al., TaX-EXempt Hospitals and Community Health Under the AfFordable Health Act: IdENTIFying and AdDressing UnMet Legal NeEds as Social DETERMINANTS OF HEALTH, 131 (2016) (reviewing key aspects of ACA and Internal Revenue Service regulations promulgated thereunder and explaining how unmet legal needs function as health determinants).

163 Beth KuTSCHER, Taking a Broader View of Health: With Less Need for Charity Care, Hospitals Focus on Community Health Improvement, MODERN HEALTHCARE, 14-18 (Nov. 23, 2015), [https://perma.cc/SJD9-ZDC5] (last visited May 7, 2016) (reviewing examples of hospitals tackling the social determinants of health). see also Stuart M. Butler, Can Hospitals Help Create 
Perhaps the most sweeping proposal for legal reform to reduce disparities has been made by Professor Dayna Bowen Matthew in the context of health care access and delivery. ${ }^{164}$ She attributes the persistence of racial disparities in health care to unconscious (or "implicit") bias, rather than explicit or conscious racism, in individuals (both providers and patients) and in institutions. Bowen offers empirical social science evidence that "confirms that the vast majority of Americans hold implicit racially biased attitudes." 165 She argues that "[w]hile implicit bias is not overt racism or bigotry, the injustice and inequality that flow from both conscious and unconscious racism are equally egregious." "6he rejects current approaches to address such implicit bias on an individual basis (e.g., through cultural-competency training programs), ${ }^{167}$ urging abandonment of "the failed educational, political, administrative, and self-regulatory approaches that have left health care disparities essentially unchanged for as long as they have been measured." 168

Instead, Bowen proposes an approach to maximize a population-wide impact on reducing implicit biases by creating a new legal cause of action for unconscious racial discrimination. Building on the antidiscrimination laws, she advocates amending Title VI, which prohibits federally funded organizations, including health care organizations, from discrimination, in order to: "(1) expressly prohibit policies and practices that have a disparate impact on the basis of race, color, or national origin; (2) restore the private cause of action for disparate impact claims . . . ; and (3) introduce a new disparate impact claim, based on a negligence standard of care." ${ }^{169}$ She draws on considerable recent scholarship from the Title VII employment discrimination literature to support her proposal and carefully counters the anticipated objections to it. ${ }^{170}$ Her proposal is

Healthy Neighborhoods?, 314 J. AM. MED. Assoc. 2949, 2494-95, (2015) (outlining steps needed if hospitals are to play their full role in improving health in their communities); C.J. Eisenbarth Hager, Hospital Community Benefit: How Partnerships Can Support Healthy Communities, HeAlth AfFAirs Blog (Oct. 22, 2015), http://healthaffairs.org [https://perma.cc/45BV-79Q2] (last visited May 7, 2016) (discussing Arizona community partnership that is comprised of people working for hospitals, banks, and insurers and in the areas of public health, transportation, and affordable housing in order to build the basis for health in lower-income communities).

${ }^{164}$ DAYna Bowen MatThew, Just Medicine: A CuRE For RACIAL INEQUALITY IN AMERICAN Health Care (N.Y. Univ. Press, 2015).

${ }^{165} \mathrm{Id}$. at 207; see also id. at 39-54.

${ }^{166} \mathrm{Id}$. at 54.

${ }^{167}$ Id. at 180 (concluding that "the record shows little evidence that the CLAS standards have any impact whatsoever on discriminatory health behaviors or inequitable patient health outcomes ... [C]ultural competence programs have little impact. Though they may reduce explicit prejudices, they are not the kind of sustained interventions that work to address implicit racial and ethnic biases."); see generally id. at 178-183.

${ }^{168} \mathrm{Id}$. at 193.

${ }^{169} I d$. at 195-96, 198 (proposing that negligence would replace the current standard of proof in disparate treatment cases, which requires evidence of intent to discriminate, and could obviate the current defense allowed in disparate impact cases of evidence of a nondiscriminatory reason for the defendant's conduct, thus "turning the law's focus to resolving discriminatory outcomes rather than discriminatory motives.").

${ }^{170} I d$. at $196-223$. 
aimed at creating fundamental structural changes in the delivery of health care through a new body of antidiscrimination law. The new legal regime would change the context in which health care decisions are made and the social norms surrounding unconscious bias: "I propose that making discrimination due to unconscious racism illegal-forbidden by explicit and enforceable law-will change the context, incentives, and outcomes in health care, and will thereby reduce health disparities." 171

\section{B. Professional and Graduate Education for the Future}

\section{Progress within the Health Professions}

Several recent national and international reports have called for education reform within the health professions, encouraging more interprofessional education. ${ }^{172}$ There has also been an encouraging recent call to break down the traditional silos between the health care and public health professions. ${ }^{173}$ These reports call for educating health professionals together across their professional boundaries on the logical, if still largely unproven, assumption that interprofessional education will improve interprofessional collaborative practice, which in turn will improve patient and population health. ${ }^{174}$ While these reports advocate the benefits of interprofessional health education to promote interprofessional health practice, collaboration, and teamwork in order to meet the needs of ever-changing and global societies, they tend to limit their targeted audiences to

${ }^{171}$ Id. at 190.

172 See, e.g., Inst. Of MED., INTERPROFESSIONAL EDUCATION FOR COLLABORATION: LEARNING How to Improve HeAlth From InTERPROFEsSIONAL MOdEls ACROSS THE CONTINUUM OF EduCATION TO PRACTICE: Workshop (Karen M. Anderson \& Steve Olson, Rapporteurs, The Nat'l Academies Press, 2013); World Health Organization, Study Group On InTERPROFESSiOnal EDUCATION AND COLlabORATIVE PRACTICE, FRAMEWORK FOR ACTION ON INTERPROFESSIONAL EdUCATION \& COLlaborative PRACTICE (hereinafter World Health Org., 2010); see also Frenk, supra note 2, at 1944 (observing that "[a]lthough simple in concept, interprofessional education is difficult to implement ... Team roles of individual health professionals have floundered amid the divided faculty and curricula of the different professions, the rigid tribalism that afflicts, them, hyperspecialisation of some professionals, and overly rigid accreditation standards that restrict opportunities for collaboration."); see also infra note 186 and accompanying text (identifying other initiatives to promote interprofessional education among health-related professionals).

${ }^{173}$ IOM Primary Care, supra note 2, at 17 (stating that "the integration of primary care and public health holds great promise as a way to improve the health of society").

174 To date, however, there has been little empirical evidence of the assumed positive correlations among interprofessional education, collaborative practice, and patient outcomes. For a recent call to strengthen this evidence base, see InST. OF MED., MEASURING THE IMPACT OF Interprofessional Education on Collaborative Practice and Patient Outcomes 8, 39 (The Nat'l Academies Press, 2015) (observing that "[a]lthough there is a widespread and growing belief that IPE may improve interprofessional collaboration, promote team-based health care delivery, and enhance personal and population health, definitive evidence linking IPE to desirable intermediate and final outcomes does not yet exist . . . The lack of a well-established causal relationship between IPE and health and system outcomes is due in part to the complexity of the environment in which education interventions are conducted."). 
health-related professionals without considering the potential benefits of including legal or public policy professionals on the educational team.

In addition to educational reform efforts to link interprofessional education with effective collaboration in practice settings, there have also been calls to increase educational attention in the health professions to the social determinants of health. Until now, the typical recommendations and efforts in professional education to reduce health disparities-including the IOM Unequal Treatment report itself-have focused on eliminating potentially discriminatory treatment-implicit bias or overt discrimination-in health care and strengthening the cultural competency of health care providers, ${ }^{175}$ rather than on educating providers to understand and address the social determinants of health disparities. This emphasis on cultural competency training to reduce health disparities may be misplaced, since the change that such trainings produce is largely in professional attitudes, which is certainly a good thing, but not an actual impact on reducing health disparities. ${ }^{176}$ By contrast, a newly-released IOM report offers a counterbalancing emphasis and directly calls

175 See generally Mary Butler et al., Improving Cultural Competence to Reduce Health Disparities: Comparative Effectiveness Review No. 170 (March 2016) (providing a literature review of studies of cultural competency trainings), https://www.effectivehealthcare.ahrq.gov [https://perma.cc/R8TQ-STAJ] (last visited May 7, 2016). The HHS Office of Minority Health has established national standards for culturally and linguistically appropriate services ("CLAS"). To aid organizations in meeting those standards, it has developed "demonstration projects, fellowship programs, training and technical assistance networks, data collection, and the development of monographs and models ... The CLAS standards are proposed as one means to correct inequities that currently exist in the provision of health services and to make these services more responsive to the individual needs of all patients/consumers." Office of Minority Health, U.S. Dep't of Health and Human Servs., National Standards for Culturally and Linguistically Appropriate Services in Healthcare: Final Report (2001), 26, 28, http://minorityhealth.hhs.gov [https://perma.cc/J3NZYNJC]. (last visited May 7, 2016); see generally U.S. Dep't of Health and Human Servs., National Culturally and Linguistically Appropriate Services Standards, HHS.GOV, https://www.thinkculturalhealth.hhs.gov [https://perma.cc/GPK3-UPXN]. Several states through legislation have mandated (California, Connecticut, New Jersey, New Mexico, and Washington) or strongly recommended (Maryland) cultural competency training for health care providers. U.S. Dep't of Health and Human Servs., Think Cultural Health: CLAS Legislation Map, HHS.GOv, https://www.thinkculturalhealth.hhs.gov [https://perma.cc/DBR2-BHR6] (last visited May 7, 2016). The Joint Commission, the accreditation body for U.S. hospitals, also endorses cultural competency training to support health care safety, quality, and equity and has established voluntary guidance for hospitals for cultural competency. The Joint Commission, Advancing Effective Communication, Cultural Competence, and Patient- and Family-Centered Care: A Roadmap for Hospitals (2010), http://www.jointcommission.org [https://perma.cc/B6XL-9P3Y] (last visited May 7, 2016).

${ }^{176}$ Butler, supra note 175 , at 70-77 (finding that "[a]though the cultural competence training is intended to improve quality of care and downstream health disparities, no studies included outcomes that demonstrated whether a health disparity gap had been reduced . . . [I]t seems problematic to use the cultural competency label to describe interventions designed to reduce disparities."); see also supra note 164. 
for all health professionals to be educated on the social determinants of health. ${ }^{177}$ Similar to the other reports calling for more interprofessional education, and more attention to effective collaboration in practice settings, this report encourages "experiential learning opportunities that are interprofessional and cross-sectoral and involve partnering with communities." 178 It emphasizes applied learning that incorporates both community engagement and collaborative learning for the benefit of the communities that are partners in this interprofessional education and for the potential to have positive impact on the social determinants of health: ${ }^{179}$

Partnerships with communities are an essential part of educating health professionals in the social determinants of health. The community becomes an equal partner in teaching health professionals, faculty, and students about its experiences and how the social determinants have shaped the lives of its members. In this way, community members educate health professionals about the priorities of the community addressing disparities stemming from the social determinants of health. ${ }^{180}$

In the future, interprofessional education to address the social determinants of health and health equity is likely to reflect the broader call for utilizing a HiAP framework for analyzing laws and policies. ${ }^{181}$ To be able to consider the health ramifications of policies in fields not directly related to health, such as education, housing, environment, and transportation, professionals in those fields will need both substantive knowledge about the impact of socioeconomic factors on health, and the ability to work interprofessionally and collaboratively across their respective sectors and agencies. ${ }^{182}$ In the future, hopefully graduate and professional education in these non-health fields, as is currently happening in the health-related disciplines, will incorporate attention to the social determinants of health and the skills of teamwork and collaborative problem-solving across disciplinary fields to address health disparities and promote health equity.

In the meantime, however, the next steps in interprofessional educational reform will be to incorporate the legal profession into the interprofessional and collaborative education team of

177 Committee on Educating Health Professionals to Address the Social Determinants of Health, Institute of Medicine, A Framework for Educating Health Professionals to Address the Social Determinants of Health, 15 (2016) (discussing that "all health professionals need to develop an understanding during their foundational education and training of the outside forces [social determinants of health] that impact a person's community's, or population's health and wellbeing.") http://www.nationalacademies.org [https://perma.cc/E2P8-E5M2].

${ }^{178}$ Id. at 9.

${ }^{179} I d$. at 61-62 (explaining that "[a]n example of applied learning is service learning that places equal emphasis on service and on learning for the benefit of all parties involved ... Engaging students through interprofessional projects in and with communities can help build the capacity of the health workforce for understanding and acting on the social determinants of health.").

${ }^{180} \mathrm{Id}$. at 65.

181 See supra notes 125-137 (discussing HiAP approach).

${ }^{182}$ Health Policy Brief, supra note 78, at 6 (observing that the "HiAP approach requires strong intersectoral and interagency collaboration, with a focus on the broader, upstream determinants of health that are thought to create greater inequities in health."). 
health care and public health professionals concerned with health equity. As policies in these fields cut across professional boundaries, and will have legal implications for implementation, lawyers can play a critical role at the intersection of these health-related professional fields.

\section{Next Steps: Incorporating the Legal Profession}

Despite a recent call by the Institute of Medicine for the reexamination of the role of law and policy in promoting public health, ${ }^{183}$ there have not been similar reports calling for the incorporation of legal and policy professionals on the interprofessional educational team to address society's health challenges. If lawyers, health care professionals, and public health practitioners are going to work together effectively on interprofessional teams to promote health equity in the future, they must be educated in the same interprofessional settings today.

Models for such interprofessional education have emerged from a unique, RWJF-supported faculty fellowship program. During the 2014-2015 academic year, I was the faculty lead and project director for this fellowship program, called The Future of Public Health Law Education, which selected ten faculty fellows across the country to develop innovative, interprofessional, and community-engaged curricula. ${ }^{184}$

The fellows held faculty appointments in schools of law, medicine, public health, and social work, and they offered their new courses and programs to an equally interprofessional set of graduate and professional students. Their curricular innovations provide a range of best practices for interprofessional education, collaborations between the academy and community partners, and models of experiential learning that emphasize the development of real-world skills and professional values. In addition to the special symposium volume of the Journal of Law, Medicine \& Ethics devoted to this faculty fellowship program, the fellows' innovations and teaching tools are shared in an online library of teaching resources. ${ }^{185}$

Many of the faculty fellows' courses incorporated community-based collaborations that provided service-learning opportunities with health departments and other state or local partners. Often the students' final reports, undertaken in interprofessional teams, were formally presented to their community collaborators, with real-world impact on issues of concern in their communities. In one fellow's course, teams of law, public health, public policy, and nursing students undertook extensive research and developed a policy report to assist a county health

${ }^{183}$ IOM Revitalizing Law and Policy, supra note 130, at 40.

${ }^{184}$ For a description of the fellowship program, see Charity Scott, Transforming the Future of Public Health Law Education through a Faculty Fellowship Program, 44, JoURNAL OF LAw, MEDICINE, AND ETHICS, 2016, at 6-17. This introductory article together with the concluding article by Nancy J. Kaufman \& Charity Scott, Innovation in Higher Education: Lessons Learned from Creating a Faculty Fellowship Program, 44, J. OF LAW, MED., AND ETHICS, 2016 at 97-106, provide a roadmap for how the faculty fellowship program was designed and implemented, an overview of the common themes that emerged from the fellows' projects, and an evaluation of the program's successes and challenges. The entire symposium volume of this Journal is devoted to the faculty fellowship program, with additional articles by the fellows, their mentors, and other program participants.

185 See Stacie P. Kershner, Best Practices for Teaching Public Health Law: Two Online Resource Libraries, 44, J. OF LAw, MED. \& ETHICS, 93, 93-96 (2016). 
department that was considering whether to regulate tattoo parlors in the community. ${ }^{186}$ Law and public health students worked collaboratively in another fellow's course to assist a county health department prepare for the law-related aspects of review by the Public Health Accreditation Board. ${ }^{187}$ Another fellow created a Health Policy Practicum in which law students engaged with a coalition of community partners to promote healthy homes and reduce the incidence of childhood asthma through policy and legal work on substandard housing conditions in the community. ${ }^{188}$ Another fellow established a medical-legal partnership between her law school and a federallyqualified health center in the local community to comprehensively address the medical, social, and legal issues that can adversely impact low-income people's health. ${ }^{189}$ Interdisciplinary teams of medical, public health, public policy, and law students worked with four different community partners in another's fellow course that focused on the role of law in either promoting or obstructing prevention of illness efforts in clinical and public health settings. ${ }^{190}$

While there have been increasing efforts towards interprofessional education in clinical health care settings, ${ }^{191}$ there are fewer models of interprofessional education for examining larger systemic health challenges facing society, particularly within disadvantaged communities. To address this gap, one fellow designed a course to enable students in social work, law, and public health to recognize the reciprocal relationships between public policy work and interprofessional collaborative practice and to clarify the specific competencies needed to equip students from diverse professional backgrounds to engage as teams to address public health policy and create effective organizational systems to promote the public's health. ${ }^{192}$

Appreciating the differences in knowledge, skills, and values among professionals-and discovering a common language they can communicate in-is key to their ability to work together as a team. Another faculty fellow is addressing lawyers' lack of familiarity with empirical methods that provide the fundamental evidence base for many public health initiatives, together with public

${ }^{186}$ Elizabeth (Bjerke) Van Nostrand, Tearing Down the Silos: An Interdisciplinary, PracticeBased Approach to Graduate School Education, 44, J. OF LAW, MED. \& ETHICS, 70-74 (2016).

187 Micah L. Berman, Combining Accreditation and Education: An Interdisciplinary Public Health Law Course, 44, J. OF LAw, MeD. \& ETHICS, 18-23 (2016).

188 Amy T. Campbell, Building a Public Health Law and Policy Curriculum to Promote Skills and Community Engagement, 44, J. OF LAW, MED. \& ETHICS, 30-34 (2016)

${ }^{189}$ Laura D. Hermer, Expanding Interdisciplinary Learning Opportunities on a Shoestring Through a Medical-Legal Partnership, 44 J. OF LAW, MED. \& ETHICS, 51-55 (2016).

${ }^{190}$ Elizabeth Tobin Tyler, Teaching Prevention: An Interdisciplinary Approach to Improving Population Health through Law and Policy, 44 J. L. MED. \& ETHICS, $62-68$ (2016).

191 See, e.g., InTERProfessional EduCATION COllaborative EXPERT PANel, Core COMPETENCIES FOR INTERPROFESSIONAL COLlabORATIVE PRACTICE: REPORT OF AN EXPERT PANEL (hereinafter Interprofessional Education Collaborative, 2011), http://www.aacn.nche.edu [https://perma.cc/2Z2T-BWQP]; JOSIAH MACY JR. FOUNDATION, CONFERENCE RECOMMENDATIONS: TRANSFORMING PATIENT CARE: Aligning INTERPROFESSIONAL EdUCATION with Clinical Practice Design (hereinafter John Macy Jr. Foundation, 2013), http://macyfoundation.org [https://perma.cc/366A-2GZS].

192 Heather A. McCabe, Seminar in Public Health Law and Policy in an Interprofessional Setting: Preparing Practitioners for Collaborative Practice at the Macro Level, 44 J. L. MED. \& ETHICs 56-61 (2016). 
health practitioners' lack of understanding of how law can impact policy development in public health. This fellow seeks to address these issues through a new course offered to law and public health students, allowing them to share their respective professional backgrounds and expertise in order to collaborate on empirical outcomes research in population health. ${ }^{193}$ Another fellow's course with social work, medicine, nursing, and law students emphasizes the formation of professional identity within their respective disciplines. ${ }^{194}$ Professional identity is often transmitted invisibly during professional education, almost by osmosis through immersion in a professional culture. Understanding the ways in which other professionals are implicitly yet fundamentally oriented to solve problems-with different mindsets, starting assumptions, goals, and methodologies-can be critical for appreciating one's own and each other's professional identities and approaches to addressing societal challenges.

Finally, new technologies offer new opportunities for virtual learning environments beyond the boundaries of bricks-and-mortar classrooms. Online education was the focus of two fellows' projects, which allowed for both faculty-student and student-student interaction and the flexibility to accommodate the individual circumstances, interests, and potential collaborative partners of different students. To increase the diversity of practitioners working in public health law, one fellow created synchronous online classes, including one on health disparities and vulnerable populations, that she offered between regular semesters and during the evenings to accommodate the needs and interests of students with diverse backgrounds. ${ }^{195}$ Another fellow has created an asynchronous online class as a complement to public health law externships that could be located at different state and local agencies or organizations and that emphasized the role of lawyers in a fundamentally healing and service-oriented profession. ${ }^{196}$

Several key components of the fellowship program were critical to its success. The fellows' deans were required to demonstrate institutional investment in their fellows' projects, which ensured their support in helping their fellows navigate the academic terrain to accomplish curricular changes. ${ }^{197}$ The fellows were paired with distinguished senior faculty in health law from across the country who acted as mentors and provided invaluable support, advice, and encouragement throughout the fellowship year. ${ }^{198}$ The program also offered the coaching services of an expert in professional and leadership development, who gave individualized coaching to the fellows on their professional development, and as they faced institutional challenges in

193 Robert Gatter, Teaching Population Health Outcomes Research, Advocacy, and the Population Health Perspective in Public Health Law, 44 J. L. Med. \& ETHICs 41-44 (2016).

194 Jennifer L. Herbst, Public Health Law as a Way to Explore and Develop Professional Identity, 44 J. L. MED. \& ETHICs 45-50 (2016).

195 Kimberly Cogdell Boies, Promoting Diversity in Public Health Law through Online Education, 44 J. L. MED. \& ETHICS 24-29 (2016).

196 Sarah Davis, Educating the New Public Health Law Professional, 44 J. L. MED. \& ETHICS 35-40 (2016).

197 Diane E. Hoffmann, The Importance of Including the Deans, 44 J. L. MED. \& ETHICs 8186 (2016).

198 Mary Crossley \& Ross D. Silverman, Reflections on Mentoring, 44 J. L. MED. \& ETHICS 76-80 (2016). 
implementing their projects. ${ }^{199}$ Finally, at the outset of the fellowship year, the fellows, their mentors, deans, and other leading faculty and practitioners in public health and public health law gathered for a ten-day summer institute. This intensive summer program helped to promote a strong and cohesive community of practice among the program participants that has lasted well beyond the fellowship year. ${ }^{200}$

The fellows' innovative curricular projects share a number of common traits that are the hallmark of best teaching practices for interprofessional education to develop effective practitioners who can address health disparities and promote health equity. These courses emphasize working in interprofessional teams of law students and health-related professional and graduate students to break down siloed approaches to solving problems, and they leverage a multiplicity of disciplinary perspectives to solve multi-faceted public health problems. They recognize that mutual trust is necessary for well-functioning teams, and that such trust rests on a foundation of understanding the respective goals, attitudes, and problem-solving approaches of the different professionals on the team. They foster students' appreciation for how the students' different professional backgrounds and roles can fit together so that the whole of their collaborative work is truly greater than the sum of their siloed parts would have been.

Through experiential learning, these new courses provide abundant opportunity for the development of professional skills and values, particularly in communication, cooperation, and respect for professional diversity. The courses are also grounded in, and responsive to, the realworld needs of their communities. They rely on the students themselves to take the lead in the students' own learning by engaging in meaningful service that impacts their communities. The courses push students out of their disciplinary comfort zones and encourage them to be open and curious about alternative ways to tackle complex problems. They emphasize the social, economic, and environmental determinants of health. They promote appreciation for how social inequities can lead to health inequities, particularly in vulnerable and marginalized communities.

These kinds of interprofessional educational experiences are exactly what we need to promote more of in our universities, for they can foster genuine professional engagement, insight, and teamwork for grappling with the society's health challenges in the future. "If the activity does not require collaboration and it does not provide real-life experiences . . . it should not be called 'interprofessional education." 201 The curricular innovations developed through these faculty fellowship programs provide strong models for the successful integration of real-world experiences and opportunities to work in collaborative interprofessional teams that will promote practice-ready professionals who can work together to reduce health disparities and achieve health equity.

\section{CONCLUSION}

Despite the seminal Heckler Report in 1985, and IOM UNEQUAL TREATMENT report in 2003, which both urged strong national efforts to reduce health disparities in this country, such disparities

${ }^{199}$ Debra Gerardi, Polishing the Apple: A Holistic Approach to Developing Public Health Law Educators as Leaders of Change, 44 J. L. MED. \& ETHICS 87-92 (2016).

200 Scott, supra note 184 , at 9-11.

${ }^{201}$ Cuff, supra note 172, at 40. 
have persisted to the present day. ${ }^{202}$ One reason for this lack of progress is that, until recently, the focus of much of the ensuing national attention has been on narrowly addressing the problem through initiatives within the health care system, rather than on the root causes of health disparities in the social, economic, and environmental determinants of health, even though health care has a relatively smaller impact on health than these other determinants.

Another related reason is that, even though these socioeconomic determinants of health are the result of entrenched institutional and structural barriers that perpetuate race- and class-based differences, until recently there have not been coordinated efforts among the professions, government agencies, non-profit organizations, and the communities most impacted by these disparities to address these barriers. Taking a health-in-all-policies approach by public and private stakeholders across both health and non-health sectors, offers a promising direction for tackling the multi-faceted challenges of the socioeconomic determinants of health. So does thoroughly examining how laws can impact these determinants and using laws and lawyers to break down the institutional and structural barriers to health equity in both the health and non-health sectors of society.

To realize the promise of more broadly-based laws and policies in support of achieving health equity, practitioners in the health-related and legal professions need to understand how to collaborate with each other. To collaborate effectively, they need to be familiar with each other's

202 As this article was going to press, the CDC issued its thirty-ninth report on the health of the nation, with a special feature on racial and ethnic health disparities. CTRS FOR DISEASE CONTROL and Prevention, Health, United States, 2015: With Special Feature on Racial and ETHNIC HEALTH DiSPARITIES (2016), http://www.cdc.gov [https://perma.cc/BD9R-PBMH]. While the report noted some declines in the gaps among racial and ethnic groups in some health measures - such as life expectancy, cigarette smoking in women, influenza vaccinations among those aged sixty-five and over, and insurance coverage - it concluded that "disparities by race and ethnicity were found in the most recent year for all ten measures, indicating that although progress has been made in the thirty years since the Heckler Report, elimination of disparities in health and access to health care has yet to be achieved." Id. at 21 . Even the progress noted may not be due to affirmative policy-based efforts to reduce health disparities. For example, with respect to reducing the gap in life expectancies between blacks and whites, this may be due in part to recently declining life expectancy among whites due to opioid overdoses and other substance abuse, and reduction in homicide deaths (though higher incarceration rates) for blacks. Sabrina Tavernise, Black Americans See Gains in Life Expectancy, THE NEW YORK TIMES, May 8, 2016), http://www.nytimes.com [https://perma.cc/DRA2-FKJ9] (quoting expert on the racial mortality gap that "it was difficult to tell whether any of the improvements were because of specific policies aimed at lifting blacks' health."); Sabrina Tavernise, White Americans Are Dying Younger as Drug and Alcohol Abuse Rises, THE NEw YORK TIMES (April 20, 2016), http://www.nytimes.com [https://perma.cc/RM8P-X2PV] (quoting expert that drug overdoses, liver disease, and suicide were the main drivers of declining life expectancy among whites); see also Anne Case \& Angus Deaton, Rising Morbidity and Mortality in Midlife Among White and Non-Hispanic Americans in the $21^{\text {st }}$ Century, vol. 112 no. 49 PNAS (Proc. OF THE NAT'L ACAD. OF SCI.), 15078, 15078 (2015), http://www.pnas.org [https://perma.cc/5PCV-C5FS] (Documenting "a marked increase in the allcause mortality of middle-aged white non-Hispanic men and women in the United States between 1999-2013 . . . This increase for whites was largely accounted for by increasing death rates from drug and alcohol poisonings, suicide, and chronic liver diseases."). 
knowledge domains, to understand their approaches to problem-solving, and to appreciate the respective skills and attitudes that each profession brings to the collaborative team.

Such interprofessional collaboration needs to begin with interprofessional education among legal and health-related professionals. To be effective, such interprofessional education needs to incorporate cross-disciplinary knowledge (including about the socioeconomic determinants of health and the role of law in addressing them), skills (particularly in teamwork and communication), and values (including professional ethics in their respective fields). To deepen learning, it needs to provide opportunities for these professionals-in-training to engage with community partners to solve real-world problems and provide real benefits to their communities.

Models for such leading-edge interprofessional education that offers experiential learning, interprofessional collaboration, and community engagement have been developed through a faculty fellowship program in public health law, called The Future of Public Health Law Education. These best practices in interprofessional education are, hopefully, the beginning of an innovative wave of educational, professional, and community-based collaborations that can speed our country's efforts to reduce health disparities and achieve health equity. 